\title{
Tecnología IgY: Estrategia en el tratamiento de enfermedades infecciosas humanas
} IgY Technology: Strategy in the treatment of human infectious diseases

Resumen: La aparición de microorganismos resistentes a antibióticos, el descubrimiento de nuevos agentes patógenos con potencial pandémico y el aumento de una población inmunocomprometida han dejado casi obsoleta la terapia antimicrobiana, terapia comúnmente usada para tratar enfermedades infecciosas. Por otro lado, las investigaciones acerca del uso del anticuerpo IgY para desarrollar inmunidad pasiva han demostrado el potencial que tiene la tecnología IgY para tratar enfermedades infecciosas víricas y bacterianas. Donde los anticuerpos $\lg Y$ de aves se destacan por su alta especificidad, rendimiento y escalabilidad de producción a menor costo, con relación a los anticuerpos lgG de mamíferos. El objetivo de esta revisión es determinar la importancia del uso de los anticuerpos lgY como tratamiento terapéutico y profiláctico frente a los patógenos causantes de infecciones virales y bacterianas en humanos, mediante la recopilación de ensayos clínicos, productos comerciales y patentes registradas en el período de 2010-2021. Finalmente, con este estudio se estableció que la tecnología lgY es una herramienta biotecnológica versátil y eficaz para tratar y prevenir enfermedades infecciosas, al reducir los síntomas y la carga del patógeno.

Palabras clave: Anticuerpo lgY, bacteria, terapia pasiva, virus.

Abstract: The emergence of antibiotic-resistant microorganisms, the discovery of new pathogens with pandemic potential, and the rise of an immunocompromised population have rendered antimicrobial therapy, a commonly used therapy to treat infectious diseases, almost obsolete. On the other hand, research into the use of IgY antibodies to develop passive immunity has demonstrated the potential of lgY technology to treat viral and bacterial infectious diseases. Avian lgY antibodies stand out for their high specificity, performance, and scalability at a lower cost relative to mammalian $\lg G$ antibodies. This review aims to compile information on the use of IgY antibodies as therapeutic and prophylactic treatment against pathogens causing viral and bacterial infections in humans by collecting clinical trials, commercial products, and patents registered in 2010-2021. Finally, this study established that IgY technology is a versatile and effective biotechnological tool to treat and prevent infectious diseases by reducing symptoms and pathogen burden.

Key words: IgY antibody, bacteria, passive therapy, virus.

\section{Introducción}

Cuando un hospedero se encuentra en desequilibrio disminuye la capacidad de protección del sistema inmunológico permitiendo la entrada de microorganismos. Estos patógenos desencadenan una infección, que se define como "la presencia y multiplicación de un microorganismo en los tejidos, fluidos o cavidades de un huésped"1. La colonización de los patógenos en conjunto con otros factores ambientales permiten la invasión del huésped generando daños a nivel local o sistémico, causando un infeccion².

Durante el siglo XIX era común el uso de sueros de origen animal (sueros heterólogos) para tratar enfermedades infecciosas, sin embargo la idea fue abandonada por la toxicidad asociada a su administración y la introducción de la quimioterapia antimicrobiana en $1909^{3}$. A pesar de todo, las infecciones virales y bacterianas siguen siendo las principales causas de mortalidad y morbilidad en el mundo, representando aún un desafío en la salud humana ${ }^{4}$. La pérdida de eficacia de la quimioterapia antimicrobiana se atribuye al aumento de individuos inmunodeprimidos, la reaparición de enfermedades que se consideraban ya erradicadas (sarampión, viruela), nuevos agentes infecciosos (SARS COV-2) y el desarrollo de resistencia a los antimicrobianos (RAM) $)^{5,6}$. Por esta razón, se busca un tratamiento capaz de reconocer epítopos específicos, y así evitar la entrada, propagación, y neutralización de factores de virulencia sin dañar las células huésped. Permitiendo que el sistema inmunológico elimine los patógenos y evite desarrollar una infección crónica.

Por otro lado surge el interés por el uso de sueros de origen animal, generado por el sistema inmune de aves, dada su capacidad para generar anticuerpos que brindan inmunidad pasiva a su descendencia ${ }^{7.8}$. Existen tres isotipos de inmunoglobulinas aviares: IgA e IgM presentes en la clara, e lgY presente en la yema; siendo este, el de principal interés terapeútico por su alta especificidad contra antígenos de mamíferos altamente conservados ${ }^{9}$. Fue así que desde 1995 se asigna el término "tecnología lgY" al proceso de producción y aplicación de anticuerpos $\lg Y$ aviares $^{10}$, reportandose aplicaciones en el área veterinaria, inmuno-diagnóstica y de investigación ${ }^{11}$.

En el año 2010 empieza el apogeo de esta tecnología en la medicina humana como alternativa al uso de antibióticos y por su bajo costo de producción ${ }^{12}$. Se ha documentado la eficacia del uso de lgY para tratar y prevenir infecciones bacterianas y víricas causantes de patologías como caries dental, periodontitis, gastritis, diarrea, entre otras ${ }^{13}$. De forma general se ha visto

\footnotetext{
${ }^{1}$ Departamento de Ciencias de la Vida y la Agricultura, Carrera de Ingeniería en Biotecnología, Universidad de las Fuerzas Armadas ESPE, Ecuador.

${ }^{2}$ Departamento de Ciencias de la Vida y la Agricultura, Carrera de Ingeniería en Biotecnología, Universidad de las Fuerzas Armadas ESPE, Ecuador y Laboratorio de Inmunología y Virología, CENCINAT, GISAH, Universidad de las Fuerzas Armadas, ESPE, Ecuador.
} 
que lgY facilita la eliminación del patógeno a través del intestino, evitando la replicación y propagación del mismo ${ }^{9}$. Se ha evaluado la administración sistémica del anticuerpo lgY aviar en comparación con lgG de mamiferos, evidenciándose una acción más rápida y local ${ }^{14}$. Asimismo, la inmunoterapia oral con IgY demostró su versatilidad y seguridad de uso al poder ser aplicada como fármaco y nutracéutico en un rango amplio de pacientes, desde recién nacidos, adultos, embarazadas hasta pacientes con inmunodeficientes e infecciones activas ${ }^{15}$.

Tras una breve descripción de la tecnología lgY, sus ventajas y aplicaciones, esta revisión resume el uso potencial de IgY aviar como inmunoterapia contra infecciones bacterianas y virales en humanos. Para ello se recopiló mediante páginas web oficiales y bases de datos científicas los principales ensayos clínicos, patentes y productos comerciales disponibles en el período de 2010-2021.

\section{Tecnología IgY}

En 1893 el científico Felix Klemperer reporta el primer uso de IgY aviar (IgY antitoxina tetánica) para generar inmunidad pasiva en ratones, permitiendo que estos sobrevivan a dosis consideradas letales de esta toxina ${ }^{16}$. Sin embargo, fue hasta el año 1959 donde el bienestar animal se convierte en una preocupación ética para la comunidad científica, lo que atrae nuevamente el interés por el experimento de Klemperer ${ }^{17}$. Fue entonces, que desde la década de 1980 se empieza a desarroLlar una amplia gama de aplicaciones para IgY, principalmente en investigación, diagnóstico e inmunoterapia en medicina veterinaria ${ }^{12,18}$.

En 1995, el Doctor Claus Staak, asigna el término "tecnología lgY" al proceso de producción y aplicación de anticuerpos IgY aviares ${ }^{10}$. De forma paralela en 1996, el Centro Europeo para la Validación de Métodos Alternativos (CEVMA) recomienda el uso de IgY como alternativa al uso de IgG de mamífero, convirtiendo la tecnología lgY en una práctica internacionalmente aceptada ${ }^{19}$. Por último, a partir del año 2010 y hasta la actualidad se ha evidenciado un incremento del uso de IgY en la medicina humana como herramienta de diagnóstico e inmunoterapia ${ }^{11,15}$.

\section{Inmunoglobulina IgY vs Inmunoglobulina IgG}

$\lg Y$ es un isotipo de inmunoglobulina secretada por aves, anfibios, reptiles y peces pulmonados ${ }^{20}$, es considerado el precursor evolutivo de IgG e IgE de mamíferos por su similitud funcional con ambos anticuerpos y a nivel estructural con $\lg \mathrm{E}^{21}$. A nivel inmunológico $\lg Y$ es el equivalente de $\lg G$ de mamíferos, sin embargo, difieren en aspectos funcionales y estructurales. Por ejemplo, IgY posee una masa molecular $(-180$ kDa) en comparación a lgG $(\sim 160 \mathrm{kDa})^{22}$ ya que posee cuatro dominios constantes en la cadena pesada ( $\mathrm{CH} 1-\mathrm{CH} 4)$ mientras que IgG solo posee tres ( $\mathrm{CH} 1-\mathrm{CH} 3)$. Asimismo, IgY carece de la región bisagra entre el dominio $\mathrm{CH} 1$ y $\mathrm{CH} 2$ al igual que lgE de mamífero ${ }^{10}$. Esta ausencia otorga a lgY una flexibilidad restringida en comparación a lgG afectando su capacidad de precipitar antígenos multivalentes ${ }^{23,24}$. No obstante, su limitada flexibilidad le ha permitido reconocer mejor los antígenos, es decir tener una alta especificidad, y además le ha otorgado una mayor resistencia a la degradación y fragmentación proteolítica, manteniéndose estable a temperaturas de entre $30-70^{\circ} \mathrm{C}$ y un $\mathrm{pH}$ de $3,5-11^{25}$.

Estas diferencias estructurales y funcionales entre los anticuerpos IgY aviar y su homólogo IgG de mamífero le han concedido ciertas ventajas, como (1) generar una mayor respuesta inmune contra epítopos de proteínas conservadas y proteínas que evaden el sistema inmune de mamíferos ${ }^{26}$, (2) disminuir la reactividad cruzada $^{27}$, (3) no activa el sistema complemento humano, y por último, (4) IgY reduce los falsos positivos en pruebas clínicas al carecer de los sitios de unión en la región Fc, por ejemplo, no reacciona con el factor reumatoide $(\mathrm{RF})^{28}$, tampoco con los receptores Fc bacterianos (proteína A y G) ${ }^{29}$ ni con los aglutinógenos eritrocitarios $\mathrm{A}$ y $\mathrm{B}^{30}$.

\section{Modo de acción de $\lg Y$}

En la actualidad, aún se desconocen los mecanismos específicos que emplea la inmunoglobulina IgY para proteger al huésped contra los patógenos ${ }^{31}$, pero se sabe de forma general que combina las funciones de lgG: opsonizar y fijar antígenos e IgE: mediar reacciones anafilácticas, específicamente las de hipersensibilidad de tipo I o inmediato ${ }^{32}$; por lo que se han propuesto mecanismos de acción generales para explicar las funciones efectoras que permiten la protección al huésped (Figura 1), como:

\section{Aglutinación}

IgY actúa como un "pegamento biológico", al aglutinar e inmovilizar los patógenos y facilitar su eliminación por el intestino ${ }^{11}$. Esto se afirma con el estudio de Tsubokura et $a l^{33}$ al desarrollar IgY-anti Campylobacter jejuni y registrar una disminución del $99 \%$ de bacterias en el intestino, y un aumento del $80-95 \%$ de bacterias en los recuentos bacterianos fecales.

\section{Bloqueo de adherencia}

Mecanismo principal de IgY, aprovecha su alta especificidad y permite unirse a epítopos particulares del patógeno, inhibiendo la adherencia de este a la superficie celular y previniendo la propagación intercelular (mecanismo común en virus) ${ }^{34}$. Por ejemplo, Xu et $a l^{9}{ }^{9}$ propone que si IgY se une a un antígeno de superficie (proteínas de la membrana, fimbrias o flagelos) que sea crucial para la colonización bacteriana, se lograría afectar las funciones normales de crecimiento, producción y liberación de toxinas.

\section{Neutralización de toxinas}

IgY puede evitar el desarrollo de una infección sin inhibir directamente al patógeno, al neutralizar las toxinas secretadas por los mismos y evitar el desarrollo de efectos fisiopatológicos que estos podrían desencadenar ${ }^{35}$. Por ejemplo, la patente W02013009843 describe las composiciones de IgY anti-LPS contra bacterias gastrointestinales en animales, demostrando ser eficaces en la disminución de toxinas y patógenos del tracto digestivo, además de registrar actividad antiinflamatoria ${ }^{36}$.

\section{Opsonización}

La unión IgY-patógeno, genera alteraciones estructurales en el patógeno tornándolo más suceptible a fagocitarse. Por ejemplo, en el estudio in vitro de Lee et al. ${ }^{37}$ se encontró que IgY- anti Salmonella typhimurium se unía a un antígeno de superficie de la membrana celular, generando alteraciones estructurales en la superficie bacteriana. Por otro lado se propone que lgY puede mejorar la capacidad fagócitica de las células inmunes del hospedero, pese a carecer del sitio de unión de la región Fc. Esto se evidencio en el estudio de Zhen et al. ${ }^{38}$ donde la IgY-anti Escherichia coli mejoró la actividad fagocitica de macrófagos y neutrófilos.

\section{Productividad de IgY de la yema del huevo}

IgY es el único anticuerpo aviar capaz de transferirse de la sangre de su progenitora a los oocitos maduros, otorgando 


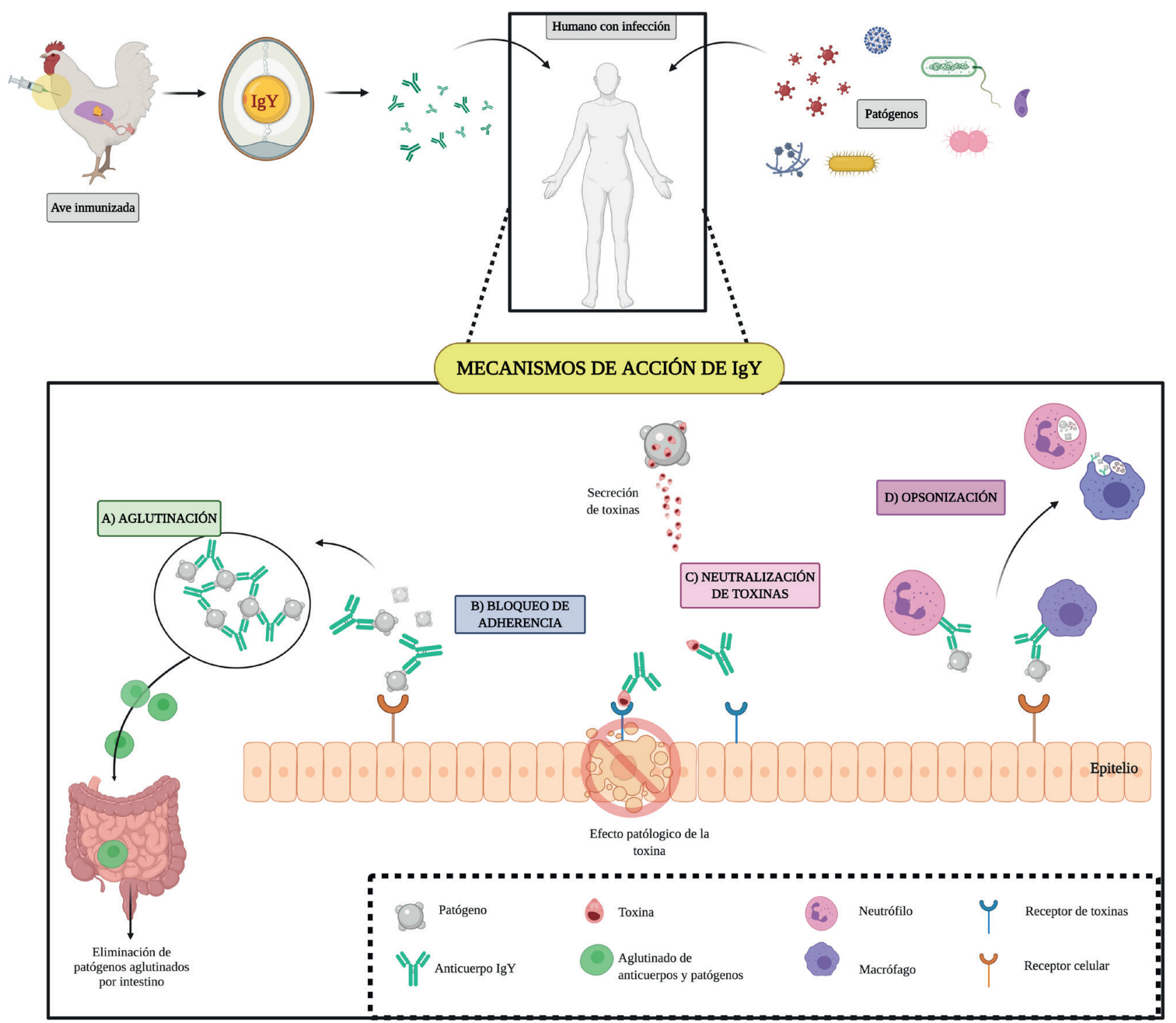

Figura 1. Mecanismos de acción de anticuerpos lgY.

protección al embrión de posibles infecciones patogénicas ${ }^{39}$. En base a este principio inmunológico y considerando que la yema de huevo es una fuente económica y accesible para obtener anticuerpos, la tecnología IgY desarrolla una metodología práctica, repetible, segura y de bajo costo para la producción de $\lg Y^{30}$. Se comienza por inmunizar a las gallinas (por vía subcutánea, intramuscular o intradérmica), con el fin de desarrollar una respuesta inmunológica adaptativa humoral ${ }^{40}$. Para ello se pueden utilizar diferentes tipos de antígenos como patógenos inactivados, proteínas recombinantes o proteínas obtenidas de ADN plasmídico ${ }^{41}$. Una vez inmunizada el ave, el antígeno se procesa y genera los anticuerpos IgY que por inmunidad pasiva se transfieren del plasma sanguíneo a la yema del huevo, este traspaso se da a partir del quinto o sexto día post inoculación ${ }^{42}$. Tras obtener el huevo, se separa la yema de la clara y se procede a remover la fracción lipídica por delipidación ${ }^{43}$. Se recupera la fracción acuosa y se precipita con polietilenglicol o sales de amonio o sodio, obteniendo un pellet de proteínas totales en donde se encuentran las $\lg \mathrm{Y}^{44}$. Por último se realiza una purificación por técnicas cromatográficas o de ultrafiltración, y se cuantifica la concentración de anticuerpo lgY obtenido ${ }^{45}$.

La eficiencia de producción de la tecnología IgY para obtener un anticuerpo con alto rendimiento, pureza y activi- dad depende de varios aspectos como (1) la raza y dieta de las aves, siendo las mejores razas de gallinas ponedoras ISA Brown y Lohmann Selected Leghorn. Por otro lado Villaguala et $a{ }^{46}$ propone evaluar la relación yema:albúmina, independientemente de la raza al considerar una relación directa para obtener una concentración mayor de lgY. (2)La modulación de la respuesta humoral donde se vio que la vía intramuscular produce niveles más altos que la subcutánea ${ }^{47}$. (3) El uso o no de inmunoestimulantes o adyuvantes, donde los adyuvantes a base de aceite, como el adyuvante completo de Freund (FCA) y el incompleto (FIA) siguen siendo los adyuvantes de elección en producción ${ }^{48}$, sin embargo, se sabe que estos desencadenan efectos secundarios en el ave. Lévesque et $a{ }^{4} .^{49}$ ha propuesto la adición de inmunoestimulantes $\mathrm{CpG}$ ODN en conjunto con el adyuvante FIA, al conseguir aumentar la producción de lgY específica hasta en un 480\%. (4) El tiempo y refuerzo del antígeno, considerando que la concentración en la yema es directamente proporcional al tiempo de exposición del antígeno en el ave ${ }^{50}$. Y por último, (5) el método de purificación aplicado, las técnicas de cromatografía y UF son útiles a nivel de laboratorio, sin embargo, la aplicación de estos métodos para la producción de lgY a gran escala se limita por problemas relacionados con la seguridad alimentaria y los altos $\operatorname{costos}^{51}$. A ni- 
vel industrial se emplean coagulantes polisacáridos naturales como pectina, alginato de sodio, goma xantana, carboximetilcelulosa y carragenina, obteniéndose una precipitación de más del $90 \%$ de las lipoproteínas de la yema ${ }^{48}$. De esta forma, la Tecnología lgY ha reportado altos rendimientos de producción, obteniendo 300-325 huevos al año por gallina inmunizada de los que se extraen de 100-150 mg de lgY por yema con una especificidad del 5 al 10\% contra el antígeno inoculado ${ }^{31,52}$.

Por otro lado, IgY se puede conservar por hasta 6 meses a temperatura ambiente, por hasta 3 meses a temperaturas de hasta $50^{\circ} \mathrm{C}$, y de $5-10$ años a $4^{\circ} \mathrm{C}^{11}$. A largo plazo se recomienda conservarlas a un máximo de $-20^{\circ} \mathrm{C}^{53}$ o liofilizadas ${ }^{44}$. En la industria farmacéutica y alimenticia es común almacenar las IgY en forma pulverizada, tras aplicar un secado por atomización ${ }^{54}$; además, se suelen adicionar estabilizadores como carbohidratos, azúcares, polioles y otros complejos, para aumentar la estabilidad térmica y de $\mathrm{pH}$ de $\lg \mathrm{Y}^{55}$.

\section{Aplicaciones de IgY}

La tecnología lgY ha evolucionado drásticamente en los últimos años, y es gracias a su estructura, propiedades y características lo que la han convertido en uno de los principales anticuerpos terapéuticos y profilácticos contra enfermedades en animales y humanos ${ }^{24}$. Ha logrado abarcar una gran variedad de campos, desde el área de diagnóstico e investigación, hasta la de producción alimenticia y farmacológica ${ }^{13}$. A continuación, se abordará de forma rápida algunas aplicaciones potenciales del anticuerpo lgY (Figura 2), para una revisión más detallada, véanse las ref. 10, 13 y 48.

\section{IgY para inmunoensayos}

La alta sensibilidad, especificidad y avidez de $\lg Y$ la han convertido en un componente esencial para inmunoensayos cuantitativos y cualitativos ${ }^{18}$. Se ha utilizado IgY como biomarcador de calidad ambiental y seguridad alimentaria ${ }^{56}$, permitiendo detectar sustancias como: fármacos residuales, alérgenos, hormonas, toxinas, antígenos (de origen viral, bacteriano, parasitario, vegetal o animal ${ }^{57-59}$, entre otros. También se ha utilizado como reactivo inmunodiagnóstico, donde la avidez de IgY con proteínas conservadas de mamíferos la han convertido en el sustituto de $\lg G$ en pruebas clínicas al eliminar falsos positivos y disminuir interferencias ${ }^{10}$, incluso se ha usado en la detección y cuantificación de biomarcadores de cáncer gástrico ${ }^{60}$, cáncer de mama y ovario ${ }^{61}$. Además, Zhang et al. ${ }^{62}$ demostró que lgY se puede utilizar como un anticuerpo secundario, al ser capaz de conjugarse con las enzimas (peroxidasa e isotiocianato), reaccionar con el anticuerpo primario (lgG de ratón) y amplificar las señales antígeno-anticuerpo.

En consecuencia, IgY ya se aplica a varios formatos de inmunoensayos, tales como: ELISA ${ }^{63}$, Western blot ${ }^{45}$, cromatografía ${ }^{64}$, ensayos inmunoenzimáticos ${ }^{65}$, ensayos de fluorescencia ${ }^{66}$, entre otros.

\section{IgY como suplemento}

El interés del consumidor por llevar un estilo de vida más sano, ha permitido que durante los últimos 20 años se produzca y utilice de forma masiva anticuerpos IgY en forma de suplemento funcional ${ }^{13}$. Se han desarrollado suplementos nutricionales, cosméticos y farmacéuticos que se pueden ingerir de forma segura, mejoran la calidad de vida de humanos y animales domésticos ${ }^{67}$.

\section{IgY como agente antitoxinas}

La administración sistemática de lgY ha reportado una nula inflamación inespecífica y un bajo índice de efectos se- cundarios $^{68}$, que en combinación con su función efectora de neutralización de toxinas la han convertido en una estrategia perfecta para el desarrollo de antídotos ${ }^{69}$. Por ejemplo, en países tropicales y subtropicales la mordedura de serpientes venenosas, escorpiones y arañas representan aún un peligro para la salud pública ${ }^{70}$, comúnmente se utilizan inyecciones con sueros producidos en caballos, cabras y ovejas, pero estos inducen efectos secundarios como la enfermedad del suero o shock anafiláctico ${ }^{71}$. Thalley et $a l^{72}$ demostró a nivel in vivo el uso de lgY como antitoxina contra serpientes cascabel y escorpiones, siendo esta capaz de neutralizar los efectos letales y actuar como antídoto de amplio espectro. De igual forma, LeClaire et $a L^{73}$ reportó el desarrollo y uso de IgY anti-enterotoxina B estafilocócica (SEB), un agente microbiano letal utilizado en guerras biológicas, donde lgY actuó como agente anti bioterrorista al reducir la cantidad de citotoxinas inflamatorias y proteger a ratones y simios de dosis letales de SEB administradas en forma de aerosol.

\section{IgY como agente antitumoral}

La supresión de la respuesta del sistema apoptótico en conjunto con la auto-renovación y supervivencia de las células tumorales, generan resistencia a la quimioterapia, tratamiento común para tumores ${ }^{74}$. Es aquí donde IgY se muestra como un potencial agente antitumoral al inducir la apoptosis en células cancerosas. Por ejemplo, Xiao et al. ${ }^{75}$ demostró que lgY anti- HER2 conjugadas con nanotubos de carbono permiten la destrucción selectiva de células de cáncer de mama. Por otro lado, Chávez et al..$^{76}$ evidenció que IgY-anti-abrina ejercia actividad citotóxica contra el biomarcador de células (CD133) en glioblastoma.

\section{IgY como agente antiobesidad}

La obesidad es una enfermedad grave de la sociedad actual, considerada como un trastorno metabólico de lípidos y enzimas; por ello se han propuesto desarrollar fármacos con inhibidores de lipasa pancreática, tanto naturales como sintéticos ${ }^{77}$. Hace poco Hirose et a $L^{78}$ desarrolló una IgY anti-lipasa, que tras probarse a nivel in vivo e in vitro, redujó el tejido adiposo y el nivel de grasa hepática en sangre. IgY actuó como agente antiobesidad, al inhibir y reducir la absorción intestinal de lipasa, y aumentar la excreción fecal de triglicéridos.

\section{IgY como agente antiinfeccioso}

La prevención y tratamiento temprano de enfermedades infecciosas es indispensable para combatir la morbilidad y la mortalidad asociada a patógenos como: virus, bacterias, parásitos y hongos ${ }^{3}$. La capacidad de IgY para neutralizar y eliminar patógenos a través del intestino lo han convertido en un potencial agente antiinfeccioso. Por ejemplo, la inmunoterapia antimicótica con lgY se ha vuelto atractiva como complemento a los fármacos antimicóticos existentes, asociada a micosis invasiva $^{79}$. Se han desarrollado preparaciones a base de $\lg Y$ que inhiben la adhesión y disminuyen la colonización del hongo Candida albicans ${ }^{80}$, un gel de uso oral desarrollado por Takeuchi et $a{ }^{81}{ }^{81}$. Asimismo se ha reportado el uso de lgY en parasitología, como método de diagnóstico temprano ${ }^{82,83}$. Thirumalai et al. ${ }^{31}$ demostró que las preparaciones de lgY policlonal son la forma más experimentada y adecuada de inmunoterapia, puesto que se pueden aislar grandes cantidades con una alta especificidad. Por ejemplo, Sampaio et $a l^{82}$ y Grando et $a l^{84}$ evaluaron el potencial terapéutico de IgY- anti Trypanosoma, a nivel in vitro e in vivo, reportando un aumento en la viabilidad de las células y la supervivencia de los animales infectados. Asimismo Espín et al. ${ }^{85}$ desarrolló una IgY anti- Leishmania 
mexicana, que permite detectar concentraciones mínimas (5$50 \mu \mathrm{g} / \mathrm{mL}$ ) del parásito.

\section{IgY para contrarrestar respuestas autoinmunes}

IgY ha demostrado un potencial para disminuir las respuestas autoinmunes asociadas a enfermedades y alérgenos. Husby et al.86 desarrolló una IgY anti-gliadina (glicoproteína presente en cereales) para tratar la enfermedad celíaca, enfermedad generada por la intolerancia al glúten, consiguiendo inhibir la absorción de gliadina y evitar la respuesta inflamatoria. Worledge et al. ${ }^{87}$ reportó el uso de lgY anti- TNFa (factor de necrosis tumoral) para tratar la enfermedad de Crohn y la colitis ulcerosa, consiguiendo un efecto preventivo y más eficaz que los fármacos antiinflamatorios. Incluso se ha desarrollado una $\lg Y$ (lgY- anti aGal) que evita el rechazo de xenotrasplantes en primates, al impedir que los anticuerpos naturales xenoreactivos interactúan con el tejido porcino trasplantado ${ }^{88}$. Por último, se ha empleado IgY como agente anti-alergénico (Figura 2), Weixu et al. ${ }^{89}$ evaluó el efecto de IgY- anti IL- $\beta 1 / T N F-a$ en cobayas con rinitis alérgica, donde observó una reducción del número de eosinófilos, neutrófilos y linfocitos en los pulmones.

\section{IgY como terapia de infecciones humanas}

En la actualidad se exige una constante demanda de terapias que desarrollen inmunidad inmediata y a largo plazo, con una producción continua y escalable, que garantice pureza y suministro constante ${ }^{90}$. Los anticuerpos lgY se muestran como una inmunoterapia pasiva prometedora y eficaz en el tratamiento de muchas infecciones ${ }^{91}$, principalmente del sistema respiratorio, digestivo y oral ${ }^{92}$. A continuación, se abordará el uso de lgY para la prevención y terapia de infecciones bacterianas y virales, mediante la recopilación de ensayos clínicos registrados (Tabla 1), patentes (Tabla 2 ) y productos comerciales (Tabla 3) desarrolladas en el periodo de 2010-2021.

\section{Infecciones bacterianas}

Los patógenos bacterianos se caracterizan por su capacidad de replicarse de forma autónoma y por secretar factores de virulencia fácilmente propagables como: toxinas, pigmentos, proteínas y moléculas de señalización ${ }^{93}$. Que en conjunto con la aparición de bacterias multirresistentes, por el uso indiscriminado de antibióticos, ha convertido las infecciones bacterianas en una amenaza para la salud pública en todo el mundo ${ }^{94}$. Como alternativa al uso de antibióticos se propone utilizar anticuerpos IgY, puesto que su capacidad de adhesión disminuye y previene la colonización bacteriana, sobre todo en la etapa inicial, impidiendo que se transformen en infecciones crónicas ${ }^{10}$.

Se ha evaluado el uso de lgY contra patógenos de la cavidad oral, tales como Prevotella intermedia ${ }^{95}$, Fusobacterium nucleatum $^{42}$, Streptococcus mutans ${ }^{96}$, Porphyromonas gingivalis $^{97}$, entre otras. Tras la administración oral de lgY en pastillas, sprays y enjuagues bucales (Tabla 1) se evitó desarrollar caries, acumular placa dental y posibles reinfecciones, incluso trataron la periodontitis y gingivitis ${ }^{98}$. Tambíen, se ha administrado IgY de forma intranasal contra patógenos del tracto respiratorio, tales como Mycobacterium tuberculosis ${ }^{99}$, Staphylococcus aureus ${ }^{100}$ y Pseudomona aeruginosa ${ }^{101}$. Donde IgY neutralizó los patógenos en el tracto respiratorio y pulmones,

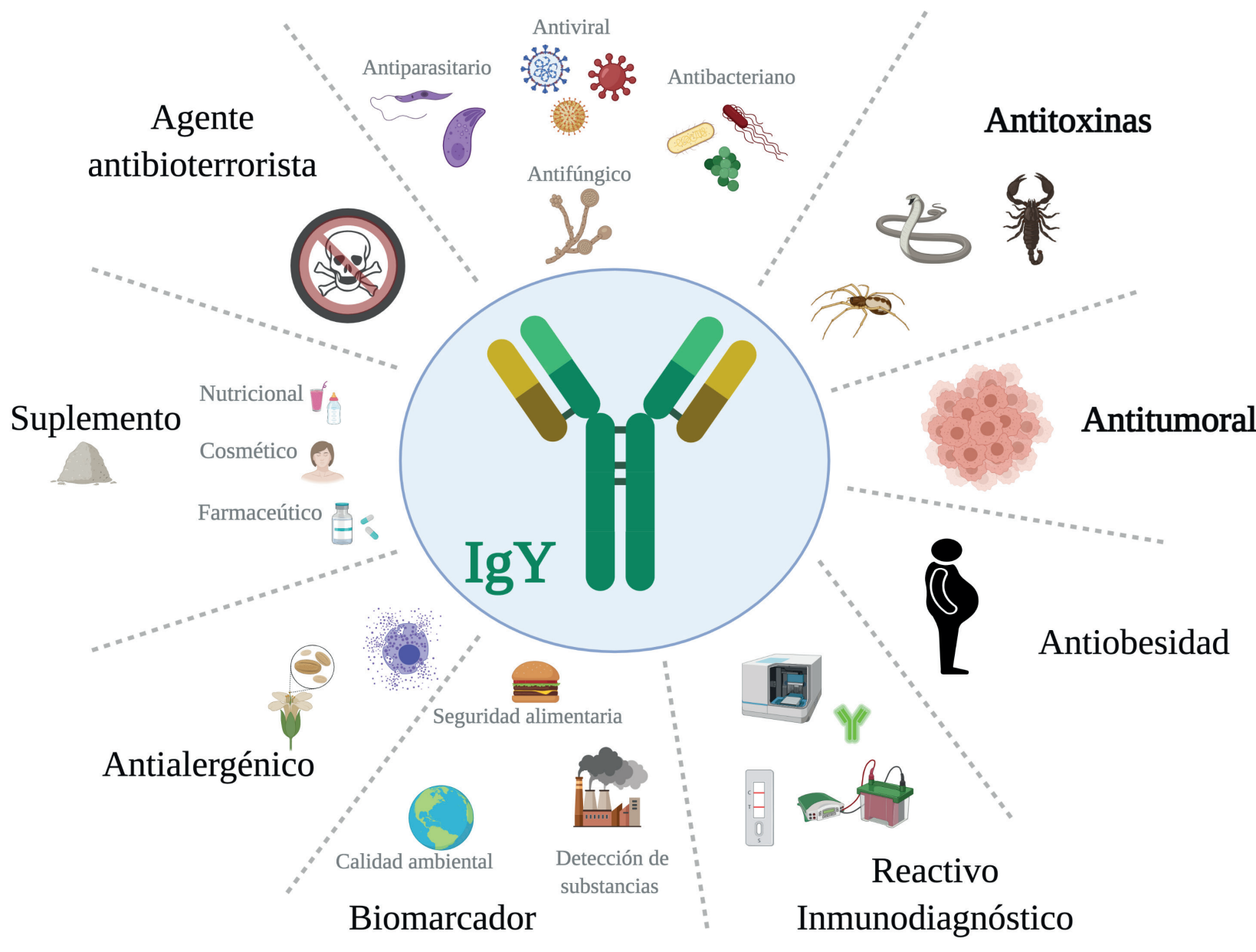

Figura 2. Aplicaciones del anticuerpo lgY. 
además se vio que al utilizar lgY como adyuvante de antibióticos este permite reducir la colonización en los pulmones ${ }^{102}$.

Por otro lado, los principales patógenos asociados a intoxicaciones alimentarias y gastritis son las bacterias gastrointestinales Escherichia coli, Salmonella spp. ${ }^{103}$, Clostridium difficile ${ }^{104}$, Helicobacter pylori105,106, Vibrio cholerae ${ }^{107}$, entre otras. Es necesario eliminar patógenos del estómago para evitar que se desarrollen afecciones más severas como úlceras y cáncer de estómago ${ }^{108}$. Se han realizado ensayos clínicos para investigar el efecto de lgY por administración oral, en fármacos (GastimunHP y GastimunHp Plus) y suplementos dietéticos (IM-01) (Tabla1), donde se evidencia de forma general que estos brindan protección contra enterobacterias y mejoran los síntomas clínicos como la diarrea ${ }^{109}$. Asimismo, se ha evaluado el uso de lgY contra bacterias asociadas al desarrollo de acné (Propionibacterium acnes) y dermatitis atópica (Staphylococcus aureus) $)^{110}$, donde IgY ha permitido controlar la secreción de enterotoxinas y mejorar la barrera cutánea ${ }^{100}$.

Finalmente, se ha evaluado el uso de lgY contra bacterias resistentes a antibióticos betalactámicos como Acinetobacter baumannii111, Klebsiella pneumoniae y Escherichia coli (Tabla 1), logrando erradicar el transporte intestinal de las enzimas BLEE (betalactamasas de expectro extendido) responsables de generar resistencia a este tipo de antibióticos ${ }^{12}$.

\section{Infecciones Virales}

Los virus son organismos contagiosos con una alta capacidad de adaptabilidad y potencial pandémico, que se caracterizan por utilizar las vías del propio huésped para replicarse y propagarse ${ }^{112}$. Pese a que ya se disponen de vacunas para algunas enfermedades virales, estas generan incertidumbre acerca de su eficacia, capacidad de producción y entrega masiva ${ }^{113}$. Es así, que en 1990 el desarrollo de lgY anti-rotavirus ${ }^{114}$ válida el uso de la tecnología IgY como tratamiento de infecciones virales, puesto que, responde a la necesidad urgente de producir anticuerpos contra componentes virales específicos en un corto tiempo, un bajo costo y sin dañar las células huésped ${ }^{92}$.

Se ha propuesto el uso de lgY para tratar infecciones causadas por virus altamente contagiosos y mortales como el ébo$\mathrm{la}^{115}$, hepatitis ${ }^{116}$, dengue $\mathrm{e}^{117,118}$, zika $\mathrm{a}^{119}$, entre otros; donde la lgY ha permitido neutralizar la replicación viral, atenuar la infección y disminuir la letalidad en infecciones leves y asintomáticas.

Ademas la administración oral de lgY para tratar infecciones gastrointestinales asociadas a rotavirus y norovirus. En el ensayo clínico del producto PTM2O2 con lgY- anti rotavirus que se probó en niños con diarrea, tras su aplicación se mejoraron los síntomas asociados como la diarrea y fiebre (Tabla 1$)^{120}$. Por otro lado, Dai et al.114 evalúo la producción a gran escala de $\lg Y$ anti-norovirus, obteniéndose en tan solo 3 meses concentraciones de 4,7-9,2 mg/mL de yema de huevo, demostrando el potencial antiviral y diagnóstico de lgY.

En infecciones respiratorias virales los primeros informes de utilización de la tecnología IgY fue hace 20 años, al aplicar IgY por administración intranasal en modelos animales y tener éxito en virus como: virus sincitial respiratorio, virus de la gripe, virus de Sendai, entre otros ${ }^{9}$. Posteriormente se logró llegar a ensayos clínicos en humanos para los virus de la influenza A (H1N121 y H5N1 ${ }^{122}$ ), influenza $B^{123}$, Hantavirus ${ }^{124,125}$, SARS ${ }^{54}$, entre otros. Donde IgY consiguió neutralizar la infectividad y reducir la replicación de estos virus en los pulmones, previniendo síndromes respiratorios agudos y graves.

\section{IgY como potencial inmunoterapia para el COVID-19}

En diciembre de 2019 en Wuhan-China se reportó un gru- po de pacientes con neumonía asociada al coronavirus del síndrome respiratorio agudo severo 2 (SARS-CoV-2) ${ }^{126}$, virus que ha mostrado una alta letalidad infecciosa y significativa mortalidad. Esta infección respiratoria se caracteriza por su alto grado de propagación y adaptabilidad, que en conjunto con las malas prácticas de bioseguridad ejecutadas por la población han permitido que se desarrolle la actual pandemia del COVID-1992. En consecuencia ha sido de suma urgencia el desarrollo de terapias y profilácticos efectivos ${ }^{127}$. En base a la experiencia con el tratamiento del SARS, Fu et al. ${ }^{54}$ propone una combinación de vacuna, inmunización pasiva y fármacos, para controlar de forma eficaz este tipo de infecciones.

La proteína pico (S) del SARS está compuesta por dos subunidades, la subunidad S1 que contiene el dominio de unión al receptor (RBD) y la subunidad S2 que media la fusión entre el virus y la célula huésped ${ }^{128}$. Por esta razón la proteína $S$ se ha convertido en el principal epítopo para desarrollar medicamentos antivirales, vacunas y anticuerpos ${ }^{129}$. Tomando en cuenta esta noción, la tecnología lgY se muestra como un potencial material clínico antiinfeccioso. Lu et al. ${ }^{130}$ desarrolló IgY-S específica para el epítopo SIIAYTMSL de la proteína S, epítopo que se superpone a la región de escisión de las subunidades S1 y S2. IgY-S exhibió una alta inmunorreactividad en ensayos ELISA y su uso permitiría prevenir la infección de las células mediante un bloqueo físico. Es decir, IgY- S evita el acceso de las enzimas proteolíticas al sitio de escisión S1/S2 y se evade la fusión de la membrana de las células y el virus. Somasundaram et al. ${ }^{131}$ propone desarrollar un anticuerpo recombinante de fragmento variable de cadena única (scFv) contra la subunidad S1, puesto que, lgY monoclonal ha demostrado ser más específica en comparación con lgY policlonal al reconocer un único epítopo. Se propone obtener esta lgY monoclonal anti S1 mediante tecnología de presentación de fagos ya que esta tecnología es más estandarizada, reproducible y adecuada para la producción a gran escala. Asimismo, a nivel preclínico se ha desarrollado el aerosol nasal IGY-110 que busca neutralizar el SARS-CoV-2 en la cavidad nasal, área primaria de infección ${ }^{132}$. Por otro lado, se ha empezado a reclutar pacientes para probar la seguridad y tolerabilidad de IgY anti-SARS-CoV-2 (Tabla 1) administrada por vía intranasal en participantes sanos, con el fin de prevenir la infección.

\section{Patentes de $\lg Y$}

IgY ha demostrado a lo largo de la historia tener un amplio potencial para desarrollar aplicaciones a base de inmunización pasiva, a partir del año 2000 el aumento de investigaciones y publicaciones ${ }^{12}$. Leiva et al. ${ }^{143}$ menciona que a partir del 2010 se empiezan a generar patentes de lgY asociadas al diagnóstico, terapia y profilaxis en medicina humana, principalmente en patologías como periodontitis, gingivitis, úlceras gástricas, infecciones asociadas al virus del papiloma humano, disbiosis, problemas nutricionales y metabólicos.

Hay que considerar que la estructura de la inmunoglobulina lgY no es patentable, no obstante, es posible patentar el método de preparación de lgY (obtención, purificación y conservación), su forma de producción y el producto a base de $\lg Y^{18}$. Por ejemplo, la solicitud de patente W02016191389 establece un nuevo método para preparar $\lg Y$ contra las bacterias causantes de periodontitis (Porphyromonas gingivalis / Streptococcus mutans/ Aggregatibacter actinomycetemcomitans) mediante la inmunización de gallinas con polipéptidos sintéticos ${ }^{144}$. Asimismo, la solicitud de patente WO2014011853 describe el método para la producción a gran escala de lgY-anti-NoV P (proteína de la cápside de norovirus) mediante la inmuniza- 


\begin{tabular}{|c|c|c|c|c|c|}
\hline Producto / Antígeno & Función & Fase / Estatus & Efecto & $\begin{array}{l}\text { Identificador / } \\
\text { Referencia }\end{array}$ & \multirow{11}{*}{$\begin{array}{l}\text { Tabla 1. Principales } \\
\text { ensayos clínicos de } \\
\text { anticuerpos lgY como } \\
\text { tratamiento terapéu- } \\
\text { tico y profiláctico de } \\
\text { infecciosas víricas y } \\
\text { bacterianas en huma- } \\
\text { nos. Se incluyó única- } \\
\text { mente ensayos clíni- } \\
\text { cos registrados en las } \\
\text { bases de datos guber- } \\
\text { namentales de Clini- } \\
\text { cal Trials de EEUU, } \\
\text { Europa y Japón du- } \\
\text { rante el periódo de } \\
\text { 2010-2021. Esta lista } \\
\text { incluye ensayos clí- } \\
\text { nicos registrados en } \\
\text { bases de datos de or- } \\
\text { ganizaciones guber- } \\
\text { namentales de EEUU } \\
\text { ( https://clinicaltrials. } \\
\text { gov/), Japón (https:// } \\
\text { www.umin.ac.jp/ctr/ } \\
\text { ) y Europa (https:// } \\
\text { www.clinicaltrialsre- } \\
\text { gister.eu/ ), las bases } \\
\text { de datos se accedie- } \\
\text { ron por última vez el } \\
\text { 15 de enero de 2021. }\end{array}$} \\
\hline $\begin{array}{l}\text { Gotero } \\
\text { IgY-anti-SARS-CoV-2 }\end{array}$ & $\begin{array}{l}\text { Prevenir el } \\
\text { síndrome } \\
\text { respiratorio agudo } \\
\text { y grave }\end{array}$ & $\begin{array}{l}\text { Fase I / } \\
\text { Reclutamiento }\end{array}$ & No disponible & NCT04567810 / 117 & \\
\hline $\begin{array}{l}\text { PTM202 } \\
\text { IgY- anti -rotavirus } \\
\text { /Escherichia coli } \\
\text { /Salmonella / Shigella }\end{array}$ & $\begin{array}{l}\text { Mejorar la diarrea } \\
\text { infantil aguda y el } \\
\text { peso de los niños }\end{array}$ & $\begin{array}{l}\text { No aplicable/ } \\
\text { Completado }\end{array}$ & $\begin{array}{l}\text { Reducción en la } \\
\text { duración de la } \\
\text { diarrea aguda no } \\
\text { sanguinolenta. }\end{array}$ & NCT02385773 / 118 & \\
\hline $\begin{array}{l}\text { IM-01 } \\
\text { IgY-anti- toxinas A y B } \\
\text { / esporas de Clostridium } \\
\text { difficile }\end{array}$ & $\begin{array}{l}\text { Mejorar síntomas } \\
\text { clínicos de diarrea }\end{array}$ & $\begin{array}{l}\text { Fase II } \\
\text { /Reclutamiento }\end{array}$ & No disponible & NCT04121169/ ${ }^{119}$ & \\
\hline $\begin{array}{l}\text { Pastilla IgY- } \\
\text { anti- gingipaína } \\
\text { Porphyromona } \\
\text { gingivalis }\end{array}$ & $\begin{array}{l}\text { Tratar la } \\
\text { periodontitis }\end{array}$ & $\begin{array}{l}\text { No aplicable / } \\
\text { Completado }\end{array}$ & $\begin{array}{l}\text { Reducción de } \\
\text { carga } \\
\text { bacteriana e } \\
\text { índice de } \\
\text { sangrado } \\
\text { gingival. }\end{array}$ & NCT02705885 / 120 & \\
\hline $\begin{array}{l}\text { Aoliding spray } \\
\text { IgY-anti-Streptococcus } \\
\text { mutans }\end{array}$ & $\begin{array}{l}\text { Prevenir caries en } \\
\text { niños en edad } \\
\text { preescolar }\end{array}$ & Fase III / Activo & No disponible & NCT02341352 / ${ }^{121}$ & \\
\hline $\begin{array}{l}\text { GastimunHP IgY-anti- } \\
\text { ureasa } \\
\text { Helicobacter pylori }\end{array}$ & $\begin{array}{l}\text { Tratar la gastritis } \\
\text { crónica }\end{array}$ & $\begin{array}{l}\text { No aplicable/ } \\
\text { Completado }\end{array}$ & No disponible & NCT02721355 / 122 & \\
\hline $\begin{array}{l}\text { GastimunHp Plus IgY- } \\
\text { anti-Helicobacter pylori }\end{array}$ & $\begin{array}{l}\text { Apoyar el } \\
\text { tratamiento de } \\
\text { úlcera péptica }\end{array}$ & $\begin{array}{l}\text { No aplica / } \\
\text { Reclutamiento }\end{array}$ & No disponible & NCT04025983 / 123 & \\
\hline $\begin{array}{l}\text { Enjuague bucal } \\
\text { IgY-anti- Pseudomona } \\
\text { aeruginosa }\end{array}$ & $\begin{array}{l}\text { Evitar infecciones } \\
\text { bucales en } \\
\text { pacientes con } \\
\text { fibrosis quística }\end{array}$ & $\begin{array}{l}\text { Fase II / } \\
\text { Completado }\end{array}$ & $\begin{array}{l}\text { Disminución del } \\
\text { tiempo para } \\
\text { contraer una } \\
\text { nueva infección } \\
\text { por bacterias u } \\
\text { hongos } \\
\text { oportunistas. }\end{array}$ & NCT00633191 / ${ }^{124}$ & \\
\hline $\begin{array}{l}\text { Enjuague bucal } \\
\text { IgY- anti- Pseudomona } \\
\text { aeruginosa }\end{array}$ & $\begin{array}{l}\text { Prolongar tiempo } \\
\text { de reinfección tras } \\
\text { infección aguda o } \\
\text { intermitente }\end{array}$ & $\begin{array}{l}\text { Fase III / } \\
\text { Completado }\end{array}$ & $\begin{array}{l}\text { Buen perfil de } \\
\text { tolerancia; pero } \\
\text { no demostró } \\
\text { beneficio en } \\
\text { pacientes con } \\
\text { fibrosis quística. }\end{array}$ & NCT01455675/125 & \\
\hline $\begin{array}{l}\text { Solución oral } \\
\text { IgY- anti- ESBL- } \\
\text { Klebsiella pneumoniae } \\
\text { y Escherichia coli }\end{array}$ & $\begin{array}{l}\text { Erradicar el } \\
\text { transporte intestinal } \\
\text { con BLEE }\end{array}$ & $\begin{array}{l}\text { Fase II / } \\
\text { Completado }\end{array}$ & No disponible & $\begin{array}{l}\text { EudraCT : 2009- } \\
011446-26 /{ }^{126}\end{array}$ & \\
\hline
\end{tabular}

ción de las gallinas con partículas recombinantes de norovirus, además estandariza las condiciones en las que lgY se logra mantener estable $\left(70{ }^{\circ} \mathrm{C}\right.$ durante 30 minutos o a un $\mathrm{pH}$ de 4-9 por $\left.3 \mathrm{~h}^{145}\right)$. En el caso de productos patentados a base de $\lg \mathrm{Y}$ tenemos la solicitud de patente CN104739719, una fórmula de una pasta de dientes a base de IgY anti-S. mutans con compuestos como lisozima y extractos de plantas.

En la tabla 2 se presentan más patentes de lgY como inmunoterapia de infecciones virales y bacterianas en humanos, para ello, se revisaron las patentes registradas entre 20102021 en la base de datos Patentscope.

\section{Productos comerciales de $\lg Y$}

Desde hace más de 20 años se ha registrado un incremento en la comercialización de lgY a nivel mundial buscando promover la salud de los seres humanos y animales ${ }^{155}$, donde se ha visto que los fundadores, líderes y expertos en tecnología IgY son los países asiáticos tales como Corea del Sur, Japón, China y Vietnam. Este incremento en la comercialización de IgY se refleja con la variedad de ensayos clínicos con resultados alentadores que se han logrado patentar y llevar al mercado como fármacos y suplementos nutracéuticos, basados en formulaciones monoespecíficas o mixtas de IgY (Tabla 3) 67,68. La administración parenteral de IgY mediante formulaciones orales e intranasales son las más comunes, ya que permiten mantener estable IgY a temperatura ambiente por más tiempo. Además, cuentan con un registro de perfil de seguridad al usar lgY en forma de huevo entero en polvo, la yema entera en polvo o únicamente la lgY purificada ${ }^{13}$.

En el ámbito veterinario se ha utilizado lgY en animales domésticos para mejorar la eficiencia de su alimentación, la tasa de crecimiento y de forma general la salud del animal ${ }^{156}$. Aquí 


\begin{tabular}{|c|c|c|c|c|}
\hline $\begin{array}{c}\text { Producto / } \\
\text { Antígeno }\end{array}$ & Compañía & Efecto & Uso & Ref. \\
\hline $\begin{array}{l}\text { Ovopron }{ }^{\circledR} \\
\text { IgY- anti- ureasa } \\
\text { Helicobacter pylori }\end{array}$ & $\begin{array}{l}\text { Pharma Foods } \\
\text { International } \\
\text { Co., Ltd. }\end{array}$ & $\begin{array}{l}\text { Erradica y previene } \\
\text { infección, úlceras gástricas y } \\
\text { duodenales. }\end{array}$ & Yogurt, tabletas & 135 \\
\hline $\begin{array}{l}\text { i26 }{ }^{\circledR} \\
\text { IgY- contra } 26 \\
\text { patógenos entéricos } \\
\text { humanos }\end{array}$ & $\begin{array}{l}\text { Arkion Life } \\
\text { Sciences }\end{array}$ & $\begin{array}{l}\text { Mejora la función digestiva, } \\
\text { equilibra la flora intestinal y } \\
\text { regula el estrés inflamatorio } \\
\text { intestinal. }\end{array}$ & Tabletas, cápsulas & 130 \\
\hline $\begin{array}{l}\text { Ovalgen } ® \mathrm{HP} \\
\text { IgY-anti- } \\
\text { Helicobacter pylori }\end{array}$ & \multirow{5}{*}{$\begin{array}{l}\text { EW Nutrition \& } \\
\text { Corporación } \\
\text { Ghen }\end{array}$} & $\begin{array}{l}\text { Fortalece sistema inmune } \\
\text { intestinal, evitando la } \\
\text { gastritis }\end{array}$ & $\begin{array}{l}\text { Yogurt, } \\
\text { comprimidos, } \\
\text { cápsulas }\end{array}$ & \multirow[t]{7}{*}{136} \\
\hline $\begin{array}{l}\text { Ovalgen }{ }^{\circledR} \mathrm{DC} \\
\text { IgY-anti- } \\
\text { Streptococcus } \\
\text { mutans }\end{array}$ & & $\begin{array}{l}\text { Cuidado bucal y salud } \\
\text { dental, evitando caries }\end{array}$ & $\begin{array}{l}\text { Yogurt, tabletas, } \\
\text { dulces, enjuague } \\
\text { bucal, pasta de } \\
\text { dientes }\end{array}$ & \\
\hline $\begin{array}{l}\text { Ovalgen }{ }^{\circledR} \mathrm{PG} \\
\text { IgY-anti- } \\
\text { Porphyromonas } \\
\text { gingivalis }\end{array}$ & & $\begin{array}{l}\text { Cuidado bucal, salud de las } \\
\text { encías, evitando } \\
\text { periodontitis y gingivitis. }\end{array}$ & $\begin{array}{l}\text { Cosméticos, tabletas, } \\
\text { goma de mascar, } \\
\text { enjuagues bucales, } \\
\text { pasta de dientes }\end{array}$ & \\
\hline $\begin{array}{l}\text { Ovalgen } ® \mathrm{FL} \\
\text { IgY-anti-Influenza }\end{array}$ & & $\begin{array}{l}\text { Prevención y mitigación de } \\
\text { infecciones del tracto } \\
\text { respiratorio, principalmente } \\
\text { gripe estacional }\end{array}$ & $\begin{array}{l}\text { Tabletas, goma de } \\
\text { mascar, filtros de } \\
\text { aire, mascarillas }\end{array}$ & \\
\hline $\begin{array}{l}\text { Ovalgen }{ } \mathrm{CA} \\
\text { IgY-anti-Candida } \\
\text { albicans }\end{array}$ & & Cuidado bucal y de la piel & $\begin{array}{l}\text { Gel dental, } \\
\text { cosméticos }\end{array}$ & \\
\hline $\begin{array}{l}\text { Ovalgen } ® \mathrm{RV} \\
\text { IgY-anti- rotavirus } \\
\text { humano }\end{array}$ & & $\begin{array}{l}\text { Fortalecimiento intestinal de } \\
\text { niños }\end{array}$ & $\begin{array}{l}\text { Leche de fórmula } \\
\text { para bebé }\end{array}$ & \\
\hline $\begin{array}{l}\text { Ovalgen }{ }^{\circledR} \mathrm{CS} \\
\text { IgY-anti-Cronobacter } \\
\text { sakazakii }\end{array}$ & & $\begin{array}{l}\text { Fortalecimiento intestinal de } \\
\text { niños }\end{array}$ & $\begin{array}{l}\text { Leche de fórmula } \\
\text { para bebé }\end{array}$ & \\
\hline $\begin{array}{l}\text { Muno-IgY TM } \\
--\end{array}$ & Life Sciences & $\begin{array}{l}\text { Suplemento dietético de } \\
\text { recuperación inmunológica }\end{array}$ & Tabletas & 137 \\
\hline $\begin{array}{l}\text { Ulcer lock }{ }^{\circledR} \text { IgY- } \\
\text { anti- ureasa- } \\
\text { Helicobacter pyloril } \\
\text { anti - O157: H7- } \\
\text { Escherichia coli /anti- } \\
\text { Salmonella }\end{array}$ & \multirow[t]{3}{*}{$\begin{array}{l}\text { DAN Biotech } \\
\text { Inc. }\end{array}$} & $\begin{array}{l}\text { Erradica y previene } \\
\text { infecciones, mejorando las } \\
\text { úlceras gástricas e } \\
\text { intoxicación alimentaria }\end{array}$ & $\begin{array}{l}\text { Aditivo alimentario } \\
\text { en polvo y líquido }\end{array}$ & 138 \\
\hline $\begin{array}{l}\quad \text { Gasto lock }{ }^{\circledR} \\
\text { IgY-anti-rotavirus/ } \\
\text { anti-Escherichia coli } \\
\text { /anti-Salmonella }\end{array}$ & & $\begin{array}{l}\text { Fortalecimiento intestinal de } \\
\text { neonatos y niños, mejorando } \\
\text { la diarrea aguda }\end{array}$ & $\begin{array}{l}\text { Leche de fórmula } \\
\text { para bebé, aditivo } \\
\text { alimentario en } \\
\text { productos lácteos y } \\
\text { postres. }\end{array}$ & 139 \\
\hline $\begin{array}{l}\text { Cleanato® } \\
\text { IgY-anti- } \\
\text { Staphylococcus } \\
\text { aureus }\end{array}$ & & $\begin{array}{l}\text { Mejora la barrera cutánea y } \\
\text { controla las enterotoxinas } \\
\text { estafilocócicas en dermatitis } \\
\text { atópica. }\end{array}$ & $\begin{array}{l}\text { Spray, cremas, } \\
\text { jabones, cosméticos }\end{array}$ & 140 \\
\hline
\end{tabular}

Tabla 2. Patentes de IgY como inmunoterapia de infecciones bacterianas y víricas en humanos. Abreviaturas NoV P: proteína de la cápside de norovirus; VPH: virus del papiloma humano ; L1: proteína de la cápside del virus del papiloma humano ; E6/E7: oncoproteínas del virus del papiloma humano. 
encontramos empresas como Aova Technologies que ofrece la línea de productos $\mathrm{BIG}^{\mathrm{TM}}$ para ganado y peces utilizados en acuicultura ${ }^{157}$. PRN Pharmacal con el suplemento alimenticio GastroMate $^{\circledR}$ que apoya la salud digestiva de perros y cachorros $^{158}$. BIOINNOVO con el polvo IgY DNT que se incorpora a la dieta láctea de terneros para controlar agentes como rotavirus A, coronavirus, Escherichia coli y Salmonella ${ }^{159}$. Trouw Nutrition con la línea Protimax ${ }^{\circledR}$ para ganado con productos como: Protimax ${ }^{\circledR}-\mathrm{T}$ Forte para aumentar el peso y prevenir infecciones por patógenos entéricos como Escherichia coli, Salmonella, Clostridium perfringens, rotavirus, coronavirus y Cryptosporidium; y EggMotion como suplemento alimenticio para la salud intestinal de mascotas ${ }^{160}$.

Igualmente, en el ámbito de la salud humana se han desarrollado una variedad de productos de consumo diario que van desde lácteos y pastillas hasta cremas, jabones y mascarillas (Tabla 3). Básicamente estos productos fortalecen el sistema inmune y previenen la adhesión de patógenos en la boca, tracto gastrointestinal y rostro67,161. Existen empresas que han desarrollado productos para uso humano y animal. Pharma Foods International Co. Ltd con el ingrediente funcional Ovopron lgY para el tratamiento y prevención de infecciones asociadas a Helicobacter pylori en humanos (Tabla 3). Arkion Life Sciences con su la línea i26 ${ }^{\circledR}$ Companion para mascotas que ayuda en la salud bucal y sensibilidad digestiva, mejorando la salud de articulaciones, piel y pelaje. Suplementos para humanos como $i 26^{\circledR}$ un suplemento probiótico y Muno-lg $Y^{\mathrm{T} M}$ como suplemento dietético ${ }^{162}$ (Tabla 3). También tenemos a EW Nutrition con la línea Globigen ${ }^{\circledR}$ para mejorar la nutrición y el estado de salud intestinal de rumiantes y porcinos jóvenes durante el período de destete. Dentro de esta línea encontramos productos como: Globigen Jump Start, Globigen Sow y Globigen Life Start. Por otro lado, desarrolló el suplemento alimenticio y cosmético Ovalgen ${ }^{\circledR}$ para el cuidado de la salud humana. Se ha utilizado Ovalgen ${ }^{\circledR}$ como ingrediente funcional de la serie de productos IgYGate ${ }^{\circledR}$ : GastimunHP y GastimunHP Plus para el tratamiento de gastritis y úlceras gástricas, IgYGate ${ }^{{ }_{-}} \mathrm{F}$ contra gripes estacionales ,y como herramienta de apoyo al tratamiento de caries y gingivitis IgYGate ${ }^{\circledR}$ DC-PG ${ }^{163}$ (Tabla 3). Por último, Dan Biotech Inc. con su línea Ig-Lock ${ }^{\circledR}$ permite prevenir y controlar infecciones intestinales asociadas a Escherichia coli, parvovirus, coronavirus y adenovirus en animales domésticos como perros, aves de corral, ganado vacuno y porcino. Por otro lado, para humanos desarrollo la línea Cleanato ${ }^{\circledR}$ para el cuidado de la piel y Ulcer lock ${ }^{\circledR}$ / Gasto lock $^{\circledR}$ para el fortalecimiento gastrointestinal ${ }^{164}$ (Tabla 3).

\section{Ventajas de la Tecnología IgY}

Como se ha visto el uso de tecnología IgY en relación a anticuerpos convencionales traen un serie de ventajas como: (1) reemplaza el sangrado de los animales por la recolección de huevos, promoviendo el bienestar animal y disminuyendo el sufrimiento asociado a manipulaciones dolorosas ${ }^{155}$, (2) se necesita una baja carga de antígeno para inducir una respuesta inmune específica ${ }^{156}$, (3) tiene una alta escalabilidad de producción a un menor costo y tiempo, aproximadamente cinco semanas desde el período de inmunización ${ }^{44}$, (4) gracias a su especificidad y acción in situ, no inducen resistencia bacteriana o alteraciones en la flora microbiana normal ${ }^{67}$, (5) no genera efectos secundarios tóxicos ya que al estar purificada no contiene albúmina, por lo que, puede incluso utilizarse en pacientes con alergia al huevo ${ }^{34}$, (6) al ser una tecnología de inmunización pasiva es aplicable en un rango de edad amplio de pacientes, desde recién nacidos hasta adultos incluidos pa- cientes inmunodeficientes y embarazadas ${ }^{92}$, (7) posee una mayor estabilidad en comparación a anticuerpos mamíferos, esto gracias a su composición genética más sencilla ${ }^{171}$, (8) tiene una amplia versatilidad permitiendo utilizarse como anticuerpo policlonal, monoclonal, fragmentado o quimérico ${ }^{172}$, y por último (9) ejerce un efecto antimicrobiano e inmunoestimulante adicional gracias a la presencia de proteínas bioactivas encontradas en las preparaciones de IgY en forma de huevo entero en polvo o yema entera en polvo, tales como fosfoproteína fosvitina ${ }^{173}$ y derivados del ácido siálico (propiedades antivirales) ${ }^{174}$.

\section{Conclusiones}

Como se ha visto desde los años 80 hasta la actualidad la tecnología IgY se ha empleado como una herramienta diagnóstica, terapéutica y profiláctica, logrando posicionarse a nivel industrial y comercial en todo el mundo. El uso de huevos como fuente de anticuerpos IgY ha permitido desarrollar una metodología de producción práctica, escalable y de bajo costo. Estos anticuerpos IgY aviar han atraído cada vez más la atención de la comunidad científica para reemplazar a los anticuerpos IgG de mamíferos, puesto que, sus particularidades estructurales y funcionales le han otorgado una mayor especificidad, baja reactividad cruzada y alta vida media circulante. En cuanto a su modo de acción se han descubierto los mecanismos de acción general, donde si bien IgY no ejerce una erradicación microbiana total permite reducir significativamente la carga de patógenos hasta el punto en el que la propia inmunidad del paciente puede erradicarlos. Se han propuesto que las funciones efectoras de IgY son: el bloqueo de adherencia del patógeno, neutralización de epítopos específicos incluidos toxinas, opsonización del patógeno y formación de aglutinados de antígenos-anticuerpos para eliminarlos a través del intestino.

Desde 2010 se registra una mayor acogida de la tecnología IgY en la medicina humana gracias a sus propiedades antiinfecciosas, antitumorales, antitoxinas, antiinflamatorias y antiobesidad. Afirmando que el uso de anticuerpos IgY permite tratar y prevenir infecciones víricas y bacterianas. Este hecho se evidencia con el incremento de ensayos clínicos, patentes y productos a base de lgY, por ejemplo, ya se comercializan una gran variedad de productos de consumo diario, tales como: fármacos, cosméticos, filtros de mascarilla, suplementos y nutracéuticos. Además el uso de lgY en lugar de antibióticos para tratar este tipo de infecciones responde a la grave problemática de salud que representa el desarrollo de patógenos resistentes a antimicrobianos.

Por último, como hemos visto el mundo se enfrenta a uno de los mayores desafíos sanitarios con la actual pandemia del COVID-19, evidenciando la necesidad urgente de nuevas o mejoradas terapias. Y como alternativa del uso de la tecnología IgY como herramienta biotecnológica segura, eficaz, económica y versátil para disminuir la incidencia, prevalencia y severidad de varias enfermedades infecciosas.

\section{Referencias bibliográficas}

1. García Palomo JD, Agüero Balbín J, Parra Blanco JA, Santos Benito MF. Enfermedades infecciosas. Concepto. Clasificación. Aspectos generales y específicos de las infecciones. Criterios de sospecha de enfermedad infecciosa. Pruebas diagnósticas complementarias. Criterios de indicación. Medicine (Baltimore) 2010; 10: 3251-3264. 


\begin{tabular}{|c|c|c|c|}
\hline Antígeno & Título & Patente & Ref \\
\hline $\begin{array}{l}\text { IgY- anti- Staphylococcus } \\
\text { aureus/Citrobacter/ } \\
\text { Corynebacteria / Klebsiella }\end{array}$ & $\begin{array}{l}\text { Composición de productos } \\
\text { farmacéuticos y cosméticos }\end{array}$ & WO2002002642 & 143 \\
\hline $\begin{array}{l}\text { IgY- anti-toxina-Clostridium } \\
\text { tetani }\end{array}$ & $\begin{array}{l}\text { Antitoxina tetánica (de origen de yema } \\
\text { de huevo de gallina) }\end{array}$ & IN1907/MUM/2006 & 144 \\
\hline IgY-anti-Helicobacter pylori & $\begin{array}{l}\text { Composición farmacéutica que } \\
\text { comprende anticuerpos IgY anti- } H \text {. } \\
\text { pylori ureasa y un inhibidor de la } \\
\text { secreción de ácido gástrico }\end{array}$ & EP1172116 & 145 \\
\hline IgY-anti-Bacillus cereus & $\begin{array}{l}\text { Generación de anticuerpos de pollo } \\
\text { contra patógenos microbianos Bacillus } \\
\text { cereus de uñas humanas }\end{array}$ & IN201941048986 & 146 \\
\hline $\begin{array}{l}\text { IgY-anti - Vibrio } \\
\text { parahaemolyticus }\end{array}$ & $\begin{array}{l}\text { Anticuerpo anti-vibrio } \\
\text { parahaemolyticus de yema de pollo, } \\
\text { método de preparación y aplicación del } \\
\text { mismo }\end{array}$ & CN101343320 & 147 \\
\hline $\begin{array}{l}\text { IgY-anti-Mycobacterium } \\
\text { tuberculosis }\end{array}$ & $\begin{array}{l}\text { Preparación inmune de anticuerpos } \\
\text { específicos IgY y su aplicación en la } \\
\text { prevención y el tratamiento de la } \\
\text { infección por Mycobacterium } \\
\text { tuberculosis }\end{array}$ & CN1569231 & 148 \\
\hline $\begin{array}{l}\text { IgY.-anti-Streptococcus } \\
\text { mutans }\end{array}$ & $\begin{array}{l}\text { Combinación de IgY contra la caries } \\
\text { dental }\end{array}$ & US20040126384 & 149 \\
\hline $\begin{array}{l}\text { IgY - anti-Porphyromonas } \\
\text { gingivalis / Fusobacterium } \\
\text { nucleatum }\end{array}$ & $\begin{array}{l}\text { Enjuague bucal para prevenir la } \\
\text { gingivitis y el mal aliento preparado con } \\
\text { anticuerpo IgY específico anti- } \\
\text { Porphyromonas gingivalis y } \\
\text { Fusobacterium mucleatum }\end{array}$ & CN102860932 & 150 \\
\hline $\begin{array}{l}\text { IgY- anti- toxinas A y B } \\
\text { Clostridium difficile }\end{array}$ & $\begin{array}{l}\text { Composiciones contra toxinas } \\
\text { bacterianas }\end{array}$ & WO2013009843 & 151 \\
\hline IgY-anti-Rotavirus $A$ & IgY contra el rotavirus & KR1020010016599 & 152 \\
\hline IgY anti-SARS-CoV & $\begin{array}{l}\text { Anticuerpo contra SARS-CoV IgY y su } \\
\text { método de preparación }\end{array}$ & CN1621417 & 153 \\
\hline $\begin{array}{l}\text { IgY-anti-partícula P- } \\
\text { Norovirus }\end{array}$ & $\begin{array}{l}\text { IgY de partículas de norovirus P y sus } \\
\text { derivados }\end{array}$ & US20140017257 & 154 \\
\hline IgY-anti-VPH & $\begin{array}{l}\text { Nuevo preparado anti-virus del } \\
\text { papiloma humano (VPH) y endometritis }\end{array}$ & CN104056268 & 155 \\
\hline $\begin{array}{l}\text { IgY-anti-VPH-L1-E6-E7 } \\
\text { (proteínas del Virus del } \\
\text { Papiloma Humano) }\end{array}$ & $\begin{array}{l}\text { Anti-HPV-L1 y E6 / E7- IgY de amplio } \\
\text { espectro, anticuerpo de molécula } \\
\text { pequeña y aplicación del mismo }\end{array}$ & CN110054686 & 156 \\
\hline
\end{tabular}

Tabla 3. Productos suplementados con IgY para uso humano. Datos tomados de la base de datos Patentscope. 
2. Dobson AP, Carper ER. Infectious Diseases and Human Population History: Throughout history the establishment of disease has been a side effect of the growth of civilization. BioScience 1996; 46: 115-126.

3. Casadevall A. Antibody-based therapies for emerging infectious diseases. Emerg Infect Dis 1996; 2: 200-208.

4. Kaufmann SHE, Dorhoi A, Hotchkiss RS, Bartenschlager R. Host-directed therapies for bacterial and viral infections. Nat Rev Drug Discov 2018; 17: 35-56.

5. Nii-Trebi Nl. Emerging and Neglected Infectious Diseases: Insights, Advances, and Challenges. BioMed Res Int 2017; 2017: 5245021.

6. Oral HB, Ozakin C, Akdiş CA. Back to the future: antibody-based strategies for the treatment of infectious diseases. Mol Biotechnol 2002; 21: 225-239.

7. Patterson R, Youngner JS, Weigle WO, Dixon FJ. Antibody Production and Transfer to Egg Yolk in Chickens. J Immunol 1962; 89: $272-278$.

8. Thomsen K, Christophersen L, Bjarnsholt T, Jensen PØ, Moser C, Høiby N. Anti-Pseudomonas aeruginosa IgY antibodies augment bacterial clearance in a murine pneumonia model. J Cyst Fibros Off J Eur Cyst Fibros Soc 2016; 15: 171-178.

9. Xu Y, Li X, Jin L, Zhen Y, Lu Y, Li S et al. Application of chicken egg yolk immunoglobulins in the control of terrestrial and aquatic animal diseases: a review. Biotechnol Adv 2011; 29: 860-868.

10. Schade R, Calzado EG, Sarmiento R, Chacana PA, Porankiewicz-Asplund J, Terzolo HR. Chicken egg yolk antibodies (IgY-technology): a review of progress in production and use in research and human and veterinary medicine. Altern Lab Anim ATLA 2005; 33: 129-154.

11. Thu HM, Myat TW, Win MM, Thant KZ, Rahman S, Umeda K et al. Chicken Egg Yolk Antibodies (IgY) for Prophylaxis and Treatment of Rotavirus Diarrhea in Human and Animal Neonates: A Concise Review. Korean J Food Sci Anim Resour 2017; 37: 1-9.

12. Leiva CL, Gallardo MJ, Casanova N, Terzolo H, Chacana P. IgY-technology (egg yolk antibodies) in human medicine: A review of patents and clinical trials. Int Immunopharmacol 2020; 81: 106269

13. Hatta H, Horimoto Y. Chapter 16: Applications of Egg Yolk Antibody $(\lg Y)$ in Diagnosis Reagents and in Prevention of Diseases. In: Eggs as Functional Foods and Nutraceuticals for Human Health. 2019, pp 305-328.

14. Rahman S, Van Nguyen S, Icatlo Jr. FC, Umeda K, Kodama Y. Oral passive IgY-based immunotherapeutics. Hum Vaccines Immunother 2013; 9: 1039-1048.

15. Muller S, Schubert A, Dyck T, Oelkrug C. IgY antibodies in human nutrition for disease prevention. Nutr J 2015; 14: 109.

16. Klemperer F. Ueber natürliche Immunität und ihre Verwerthung für die Immunisirungstherapie. Arch Für Exp Pathol Pharmakol 1893; 31: 356-382.

17. Schade R, Hlinak A. Egg Yolk Antibodies, State of the Art and Future Prospects. ALTEX 1996; 13: 5-9.

18. Schade R, Terzolo H. IgY-technology: application and trends [Internet]. 2006. Available from: https://www.researchgate.net/ publication/267702265_IgY-technology_application_and_trends

19. Schade R, Staak C, Hendriksen C, Erhard M, Hugl H, Koch G et al. La producción de anticuerpos aviares (yema de huevo): IgY: Informe y recomendaciones del taller ECVAM 21 1,2. Altern Lab Anim 1996; 24: 925-934.

20.Warr G, Magor K, Higgins D. IgY: clues to the origins of modern antibodies. Immunol Today 1995; 16: 392-398.

21. Pereira EPV, Van Tilburg MF, Florean EOPT, Guedes MIF. Egg yolk antibodies (IgY) and their applications in human and veterinary health: A review. Int Immunopharmacol 2019; 73: 293-303.

22. Sun S, Mo W, Ji Y, Liu S. Preparation and mass spectrometric study of egg yolk antibody (lgY) against rabies virus. Rapid Commun Mass Spectrom RCM 2001; 15: 708-712.

23. Faith RE, Clem LW. Passive cutaneous anaphylaxis in the chicken. Immunology 1973; 25: 151-164.

24. Spillner E, Braren I, Greunke K, Seismann H, Blank S, du Plessis D. Avian IgY antibodies and their recombinant equivalents in research, diagnostics and therapy. Biologicals 2012; 40: 313-322.
25. Hernández Castillo LM, Duque Restrepo AM, Martínez Delgado CM. Tecnología IgY para el control de enfermedades infecciosas como la caries dental. Tesis [Internet]. Universidad CES. 2015. Available from: https://repository.ces.edu.co/handle/10946/390

26. Sesarman A, Mihai S, Chiriac MT, Olaru F, Sitaru AG, Thurman JM et al. Binding of avian IgY to type VII collagen does not activate complement and leucocytes and fails to induce subepidermal blistering in mice. Br J Dermatol 2008; 158: 463-471.

27. Chacana P, Terzolo H, Gutierrez E. Tecnología IgY o aplicaciones de los anticuerpos de yema de huevo de gallina. Rev Med Vet 2004; 85: 179-189.

28. Nguyen HH, Tumpey TM, Park H-J, Byun Y-H, Tran LD, Nguyen VD et al. Prophylactic and Therapeutic Efficacy of Avian Antibodies Against Influenza Virus H5N1 and H1N1 in Mice. PLoS ONE 2010; 5. doi:10.1371/journal.pone.0010152.

29. Carlander D, Stålberg J, Larsson A. Chicken Antibodies: A Clinical Chemistry Perspective. Ups J Med Sci 1999; 104: 179-189.

30.Contreras VT, Lima ARD, Navarro MC, Arteaga RY, Graterol D, Cabello $L$ et al. Producción y purificación de anticuerpos ( $\lg Y)$ a partir de huevos de gallinas inmunizadas con epimastigotas de Trypanosoma cruzi. Salus 2005; 9: 21-27.

31. Thirumalai D, Visaga Ambi S, Vieira-Pires RS, Xiaoying Z, Sekaran $\mathrm{S}$, Krishnan U. Chicken egg yolk antibody (IgY) as diagnostics and therapeutics in parasitic infections - A review. Int J Biol Macromol 2019; 136: 755-763.

32. Lundqvist ML, Middleton DL, Radford C, Warr GW, Magor KE. Immunoglobulins of the non-galliform birds: Antibody expression and repertoire in the duck. Dev Comp Immunol 2006; 30: 93-100.

33. Tsubokura K, Berndtson E, Bodgstedt A, Kaijser B, Kim M, Ozeki $M$ et al. Oral administration of antibodies as prophylaxis and therapy in Campylobacter jejuni-infected chickens. Clin Exp Immunol 1997; 108: 451-455.

34.Abbas AT, El-Kafrawy SA, Sohrab SS, Azhar EIA. IgY antibodies for the immunoprophylaxis and therapy of respiratory infections. Hum Vaccines Immunother 2018; 15: 264-275.

35. Arimitsu H, Sasaki K, Kohda T, Shimizu T, Tsuji T. Evaluation of Shiga toxin 2e-specific chicken egg yolk immunoglobulin: Production and neutralization activity. Microbiol Immunol 2014; 58: 643-648.

36. Mitteness BM, Phillips C., Inventors; Camas Incorporated, assignee: Compositions Against Bacterial Toxins. World Intellectual Property Organization patent WO 2013009843. 2013 Jan 7.

37. Lee EN, Sunwoo HH, Menninen K, Sim JS. In vitro studies of chicken egg yolk antibody (lgY) against Salmonella enteritidis and Salmonella typhimurium. Poult Sci 2002; 81: 632-641.

38.Zhen Y-H, Jin L-J, Guo J, Li X-Y, Lu Y-N, Chen J et al. Characterization of specific egg yolk immunoglobulin (lgY) against mastitis-causing Escherichia coli. Vet Microbiol 2008; 130: 126-133.

39. Murai A. Maternal Transfer of Immunoglobulins into Egg Yolks of Birds. J Poult Sci 2013; 50: 185-193.

40.Ferreira Á, Santos JP, Sousa L de O, Martin I, Alves EGL, Rosado IR. Gallus gallus domesticus: immune system and its potential for generation of immunobiologics. Ciênc Rural 2018; 48. doi:10.1590/0103-8478cr20180250.

41. Nakamura R, Pedrosa-Gerasmio IR, Alenton RRR, Nozaki R, Kondo H, Hirono I. Anti-PirA-like toxin immunoglobulin (IgY) in feeds passively immunizes shrimp against acute hepatopancreatic necrosis disease. J Fish Dis 2019; 42: 1125-1132.

42.Xu FX, Xu YP, Jin LJ, Liu H, Wang LH, You JS et al. Effectiveness of egg yolk immunoglobulin (lgY) against periodontal disease-causing Fusobacterium nucleatum. J Appl Microbiol 2012; 113: 983-991.

43.Barroso P, Murcia H, Vega N, Pérez G. Purification of lgY against Salvia bogotensis lectin. Biomédica 2005; 25: 496-510.

44.Pauly D, Chacana PA, Calzado EG, Brembs B, Schade R. IgY Technology: Extraction of Chicken Antibodies from Egg Yolk by Polyethylene Glycol (PEG) Precipitation. J Vis Exp JoVE 2011. doi:10.3791/3084. 
45.Tong C, Geng F, He Z, Cai Z, Ma M. A simple method for isolating chicken egg yolk immunoglobulin using effective delipidation solution and ammonium sulfate. Poult Sci 2015; 94: 104-110.

46. Villaguala C, González C, Pastene E, Farías C, Sáez K, Retamal-Díaz A et al. Obtención de inmunoglobulinas de yema de huevo contra Helicobacter pylori producidos en gallinas araucanas. Arch Med Vet 2016; 48: 79-88.

47. Chang HM, Ou-Yang RF, Chen YT, Chen CC. Productivity and some properties of immunoglobulin specific against Streptococcus mutans serotype $\mathrm{c}$ in chicken egg yolk (IgY). J Agric Food Chem 1999; 47: 61-66.

48. Kovacs-Nolan J, Mine Y. 17 - Using egg IgY antibodies for health, diagnostic and other industrial applications. In: Van Immerseel $F$, Nys Y, Bain M (eds). Improving the Safety and Quality of Eggs and Egg Products. Woodhead Publishing, 2011, pp 346-373.

49.Lévesque S, Martinez G, Fairbrother JM. Improvement of adjuvant systems to obtain a cost-effective production of high levels of specific IgY. Poult Sci 2007; 86: 630-635.

50. Agrawal R, Hirpurkar SD, Sannat C, Gupta AK. Comparative study on immunoglobulin $Y$ transfer from breeding hens to egg yolk and progeny chicks in different breeds of poultry. Vet World 2016; 9: 425-431.

51. Hatta H, Kapoor MP, Juneja LR. Bioactive Components in Egg Yolk. In: Egg Bioscience and Biotechnology. John Wiley \& Sons, Ltd, 2008, pp 185-237.

52. Amro WA, Al-Qaisi W, Al-Razem F. Production and purification of IgY antibodies from chicken egg yolk. J Genet Eng Biotechnol 2018; 16: 99-103.

53. Rose ME, Orlans E, Buttress N. Immunoglobulin classes in the hen's egg: Their segregation in yolk and white. Eur $\mathrm{J}$ Immunol 1974; 4: 521-523.

54.Fu C-Y, Huang H, Wang X-M, Liu Y-G, Wang Z-G, Cui S-J et al. Preparation and evaluation of anti-SARS coronavirus IgY from yolks of immunized SPF chickens. J Virol Methods 2006; 133: 112-115.

55. Yokoyama H, Peralta RC, Diaz R, Sendo S, Ikemori Y, Kodama Y. Passive protective effect of chicken egg yolk immunoglobulins against experimental enterotoxigenic Escherichia coli infection in neonatal piglets. Infect Immun 1992; 60: 998-1007.

56. Mudili V, Makam SS, Sundararaj N, Siddaiah C, Gupta VK, Rao PVL. A novel IgY-Aptamer hybrid system for cost-effective detection of SEB and its evaluation on food and clinical samples. Sci Rep 2015; 5: 15151.

57. Caza J, Fernandez R, Torres M, Muñoz D, Ortiz Tirado J, Bangeppagari $\mathrm{M}$ et al. The development, purification and characterization of anti- vitellogenin antibodies raised in hens (gallus gallus domesticus) against tilapia (oreochromis niloticus) vitellogenin protein. J Microbiol Biotechnol Food Sci 2018. doi:10.15414/ jmbfs.2019.8.5.1165-1168.

58. He J, Hu J, Thirumalai D, Schade R, Du E, Zhang X. Development of indirect competitive ELISA using egg yolk-derived immunoglobulin (IgY) for the detection of Gentamicin residues. J Environ Sci Health B 2016; 51: 8-13.

59.Li C, Zhang Y, Eremin SA, Yakup O, Yao G, Zhang X. Detection of kanamycin and gentamicin residues in animal-derived food using IgY antibody based ic-ELISA and FPIA. Food Chem 2017; 227: 48-54.

60.Noack F, Helmecke D, Rosenberg R, Thorban S, Nekarda H, Fink $U$ et al. CD87-positive tumor cells in bone marrow aspirates identified by confocal laser scanning fluorescence microscopy. Int J Oncol 1999; 15: 617-623.

61. Pan Z-L, Ji X-Y, Shi Y-M, Zhou J, He E, Skog S. Serum thymidine kinase 1 concentration as a prognostic factor of chemotherapy-treated non-Hodgkin's lymphoma patients. J Cancer Res Clin Oncol 2010; 136: 1193-1199.

62.Zhang Q, He D, Xu L, Ge S, Wang J, Zhang X. Generation and evaluation of anti-mouse $\lg G \lg Y$ as secondary antibody. Prep Biochem Biotechnol 2020; 50: 788-793.

63. Ferreira Júnior A, Santos JP, Bassi PB, F.F.Bittar J, Bittar ER. IgY-Technology Applied to Studies of Toxoplasma gondii Infection. Toxoplasmosis 2017. doi:10.5772/67997.
64.Nagaraj S, Ramlal S, Kingston J, Batra HV. Development of IgY based sandwich ELISA for the detection of staphylococcal enterotoxin G (SEG), an egc toxin. Int J Food Microbiol 2016; 237: 136-141.

65. He J, Wang Y, Sun S, Zhang X. Evaluation of Chicken IgY Generated Against Canine Parvovirus Viral-Like Particles and Development of Enzyme-Linked Immunosorbent Assay and Immunochromatographic Assay for Canine Parvovirus Detection. Viral Immunol 2015; 28: 489-494.

66. Silva A dos S da, Vasconcelos GALBM de, Kappel LA, Pinto MA, Paula VS de. An immunoenzymatic assay for the diagnosis of hepatitis A utilising immunoglobulin Y. Mem Inst Oswaldo Cruz 2012; 107: 960-963.

67. Rahman S, Nguyen S, Icatlo F, Umeda K, Kodama Y. Oral passive IgY-based immunotherapeutics. Hum Vaccines Immunother 2013; 9. doi:10.4161/hv.23383

68. Kovacs-Nolan J, Phillips M, Mine Y. Advances in the value of eggs and egg components for human health. J Agric Food Chem 2005; 53: 8421-8431.

69. Araújo AS, Lobato ZIP, Chávez-Olórtegui C, Velarde DT. Brazilian IgY-Bothrops antivenom: Studies on the development of a process in chicken egg yolk. Toxicon Off J Int Soc Toxinology 2010; 55: 739-744.

70. Gutiérrez JM, Theakston RDG, Warrell DA. Confronting the neglected problem of snake bite envenoming: the need for a global partnership. PLoS Med 2006; 3: e150.

71. Alvarez A, Montero Y, Jimenez E, Zerpa N, Parrilla P, Malavé C. IgY antibodies anti-Tityus caripitensis venom: purification and neutralization efficacy. Toxicon Off J Int Soc Toxinology 2013; 74: 208-214.

72. Thalley BS, Carroll SB. Rattlesnake and scorpion antivenoms from the egg yolks of immunized hens. Biotechnol Nat Publ Co 1990; 8: 934-938.

73. LeClaire RD, Hunt RE, Bavari S. Protection against Bacterial Superantigen Staphylococcal Enterotoxin B by Passive Vaccination. Infect Immun 2002; 70: 2278-2281.

74. Yang J, Jin Z, Yu Q, Yang T, Wang H, Liu L. The selective recognition of antibody lgY for digestive system cancers. Chin J Biotechnol 1997; 13: 85-90.

75. Xiao Y, Gao X, Taratula O, Treado S, Urbas A, Holbrook RD et al. Anti-HER2 IgY antibody-functionalized single-walled carbon nanotubes for detection and selective destruction of breast cancer cells. BMC Cancer 2009; 9: 351

76. Chavez Cortez E-G, Vargas Felix G, Rangel López E, Sotelo J, Martínez-Canseco C, Pérez-de la Cruz V et al. Production and Evaluation of an Avian IgY Immunotoxin against CD133+ for Treatment of Carcinogenic Stem Cells in Malignant Glioma: IgY Immunotoxin for the Treatment of Glioblastoma. J Oncol 2019. doi:10.1155/2019/2563092.

77. Rb B, Kk B. Pancreatic lipase inhibitors from natural sources: unexplored potential. Drug Discov Today 2007; 12: 879-889.

78. Hirose M, Ando T, Shofiqur R, Umeda K, Kodama Y, Nguyen SV et al. Anti-obesity activity of hen egg anti-lipase immunoglobulin yolk, a novel pancreatic lipase inhibitor. Nutr Metab 2013; 10: 70.

79. Datta K, Hamad M. Immunotherapy of Fungal Infections. Immunol Invest 2015; 44: 738-776.

80. Kamikawa Y, Fujisaki J, Nagayama T, Kawasaki K, Hirabayashi D, Hamada T et al. Use of Candida-specific chicken egg yolk antibodies to inhibit the adhering of Candida to denture base materials: prevention of denture stomatitis. Gerodontology 2016; 33: 342-347.

81. Takeuchi S, Motohashi J, Kimori H, Nakagawa Y, Tsurumoto A. Effects of oral moisturising gel containing egg yolk antibodies against Candida albicans in older people. Gerodontology 2016; 33: 128-134.

82. Sampaio LCL, Baldissera MD, Grando TH, Gressler LT, Capeleto $\mathrm{D}$ de $\mathrm{M}$, de Sa MF et al. Production, purification and therapeutic potential of egg yolk antibodies for treating Trypanosoma evansi infection. Vet Parasitol 2014; 204: 96-103.

83. Wolf Nassif P, DE Mello TFP, Navasconi TR, Mota CA, Demarchi IG, Aristides SMA et al. Safety and efficacy of current alternatives in the topical treatment of cutaneous leishmaniasis: a systematic review. Parasitology 2017: 144: 995-1004.

84. Grando TH, Baldissera MD, de Sá MF, do Carmo GM, Porto BCZ, Aguirre GSV et al. Avian antibodies (IgY) against Trypanosoma cruzi: Purification and characterization studies. J Immunol Methods 2017; 449: 56-61. 
85. Espín Arroba S, Ayala L, Ortíz M, Seqqat R, Torres Arias M. Characterization and Immunologic Response of IgY Against Leishmania Mexicana. Appl Med Res 2021; 8: 86-89.

86. Husby S, Koletzko S, Korponay-Szabó IR, Mearin ML, Phillips A, Shamir R et al. European Society for Pediatric Gastroenterology, Hepatology, and Nutrition guidelines for the diagnosis of coeliac disease. J Pediatr Gastroenterol Nutr 2012; 54: 136-160.

87. Worledge KL, Godiska R, Barrett TA, Kink JA. Oral administration of avian tumor necrosis factor antibodies effectively treats experimental colitis in rats. Dig Dis Sci 2000; 45: 2298-2305.

88. Fryer J, Firca J, Leventhal J, Blondie B, Malcolm A, Ivancic D et al. IgY antiporcine endothelial cell antibodies effectively block human antiporcine xenoantibody binding. Xenotransplantation 1999; 6: 98-109.

89. Wei-xu H, Wen-yun Z, Xi-ling Z, Zhu W, Li-hua W, Xiao-mu W et al. Anti-Interleukin-1 Beta/Tumor Necrosis Factor-Alpha IgY Antibodies Reduce Pathological Allergic Responses in Guinea Pigs with Allergic Rhinitis. Mediators Inflamm 2016. doi:10.1155/2016/3128182.

90.Bentes GA, Lanzarini NM, Lima LRP, Manso PP de A, da Silva A dos S, Mouta $S$ da $S$ e et al. Using immunoglobulin $Y$ as an alternative antibody for the detection of hepatitis A virus in frozen liver sections. Mem Inst Oswaldo Cruz 2015; 110: 577-579.

91. Casadevall A, Scharff MD. Return to the past: the case for antibody-based therapies in infectious diseases. Clin Infect Dis Off Publ Infect Dis Soc Am 1995; 21: 150-161.

92.Constantin C, Neagu M, Diana Supeanu T, Chiurciu V, A. Spandidos $D . \lg Y$ - turning the page toward passive immunization in COVID-19 infection (Review). Exp Ther Med 2020; 20: 151-158.

93. Bebbington C, Yarranton G. Antibodies for the treatment of bacterial infections: current experience and future prospects. Curr Opin Biotechnol 2008; 19: 613-619.

94. Munita JM, Arias CA. Mechanisms of Antibiotic Resistance. Microbiol Spectr 2016; 4. doi:10.1128/microbiolspec.VMBF-0016-2015.

95. Hou Y-Y, Zhen Y-H, Wang D, Zhu J, Sun D-X, Liu X-T et al. Protective effect of an egg yolk-derived immunoglobulin (IgY) against Prevotella intermedia-mediated gingivitis. J Appl Microbiol 2014; 116: 1020-1027.

96. Bachtiar EW, Bachtiar BM, Soejoedono RD, Wibawan IW, Afdhal A. Biological and Immunogenicity Property of IgY Anti S. mutans ComD. Open Dent J 2016; 10: 308-314.

97. Sandoval R. Inmunoterapia sintética para infecciones por bacterias gram-positivas y gram-negativas. Ecuad ES Calid Rev Científica Ecuat 2020; 7. doi:10.36331/revista.v7i1.93.

98. Schade R, Zhang X-Y, Terzolo HR. Use of IgY Antibodies in Human and Veterinary Medicine. In: Huopalahti R, López-Fandiño R, Anton M, Schade R (eds). Bioactive Egg Compounds. Springer: Berlin, Heidelberg, 2007, pp 213-222.

99.Sudjarwo SA, Eraiko K, Sudjarwo GW, Koerniasari. The Activity of Immunoglobulin Y Anti-Mycobacterium tuberculosis on Proliferation and Cytokine Expression of Rat Peripheral Blood Mononuclear Cells. Pharmacogn Res 2017; 9: S5-S8.

100. Guimarães MCC, Amaral LG, Rangel LBA, Silva IV, Matta CGF, Matta MF de R. Growth inhibition of Staphylococcus aureus by chicken egg yolk antibodies. Arch Immunol Ther Exp (Warsz) 2009; 57: 377-382.

101. Norouzi F, Behrouz B, Ranjbar M, Mousavi Gargari SL. Immunotherapy with IgY Antibodies toward Outer Membrane Protein F Protects Burned Mice against Pseudomonas aeruginosa Infection. J Immunol Res 2020; 2020: 7840631.

102. Sugita-Konishi Y, Shibata K, Yun SS, Hara-Kudo Y, Yamaguchi K, Kumagai S. Immune Functions of Immunoglobulin Y Isolated from Egg Yolk of Hens Immunized with Various Infectious Bacteria. Biosci Biotechnol Biochem 1996; 60: 886-888.

103. Esmailnejad A, Abdi-Hachesoo B, Hosseini Nasab E, Shakoori M. Production, purification, and evaluation of quail immunoglobulin $Y$ against Salmonella typhimurium and Salmonella enteritidis. Mol Immunol 2019; 107: 79-83.

104. Marjorie Pizarro-Guajardo, Díaz-González F, Álvarez-Lobos M, Paredes-Sabja D. Characterization of Chicken IgY Specific to Clostridium difficile R20291 Spores and the Effect of Oral Administration in Mouse Models of Initiation and Recurrent Disease. Front Cell Infect Microbiol 2017; 7. doi:10.3389/fcimb.2017.00365.
105. Hong KS, Ki M-R, Ullah HMA, Lee E-J, Kim YD, Chung M-J et al. Preventive effect of anti-VacA egg yolk immunoglobulin (IgY) on Helicobacter pylori-infected mice. Vaccine 2018; 36: 371-380.

106. Malekshahi ZV, Gargari SLM, Rasooli I, Ebrahimizadeh W. Treatment of Helicobacter pylori infection in mice with oral administration of egg yolk-driven anti-UreC immunoglobulin. Microb Pathog 2011; 51: 366-372.

107. Pu M. Generation and Characterization of specific Chicken Egg Yolk Antibodies (IgY) against Microbial Bio-terroristic Agent (Vibrio cholerae). Res J Anim Vet Fish Sci 2014; 2: 2320-6535.

108. Uemura N, Okamoto S, Yamamoto S, Matsumura N, Yamaguchi S, Yamakido M et al. Helicobacter pylori infection and the development of gastric cancer. N Engl J Med 2001; 345: 784-789.

109. Gordon G, Morán G, Ayala L, Seqqat R, Fernández R, Torres $M$. Generation and Characterization of IgY antibodies from Lohmann Brown Hens Immunized with Salmonella spp. for their Subsequent Application in Nanotherapy. Biol Med 2016; 80. doi:10.4172/0974-8369.1000284.

110. Revathy J, Karthika S, Sentila R, Michael A. In vitro evaluation of the efficacy of chicken egg yolk antibodies (IgY) generated against Propionibacterium acnes. Int J Cosmet Sci 2014; 36: 68-73.

111. Shi H, Zhu J, Zou B, Shi L, Du L, Long Y et al. Effects of specific egg yolk immunoglobulin on pan-drug-resistant Acinetobacter baumannii. Biomed Pharmacother 2017; 95: 1734-1742.

112. Shahani L, Heredia EJ, Chemaly RF. Antiviral therapy for respiratory viral infections in immunocompromised patients. Expert Rev Anti Infect Ther 2017; 15: 401-415.

113. Dubé E, Laberge C, Guay M, Bramadat P, Roy R, Bettinger J. Vaccine hesitancy: an overview. Hum Vaccines Immunother 2013; 9: 1763-1773.

114. Dai Y-C, Zhang X-F, Tan M, Huang P, Lei W, Fang $\mathrm{H}$ et al. A Dual Chicken IgY Against Rotavirus and Norovirus. Antiviral Res 2013; 97: 293-300.

115. Zhang Y, Wei Y, Li Y, Wang X, Liu Y, Tian D et al. IgY antibodies against Ebola virus possess post-exposure protection and excellent thermostability. bioRxiv 2020 . doi:10.1101/2020.05.21.108159

116. Chen DCP., Inventor; Asia Hepato Gene Co., assignee: Compositions and Methods for Treating Hepatitis Virus Infection. World Intellectual Property Organization patent WO 2012016429. 2012 Feb 9.

117. Fink AL, Williams KL, Harris E, Alvine TD, Henderson T, Schiltz $\mathrm{J}$ et al. Dengue virus specific IgY provides protection following lethal dengue virus challenge and is neutralizing in the absence of inducing antibody dependent enhancement. PLoS Negl Trop Dis 2017; 11. doi:10.1371/journal.pntd.0005721.

118. O'Donnell KL, Fink A, Nilles ML, Bradley DS. Dengue NS1-specific IgY antibodies neutralizes dengue infection without inducing antibody dependent enhancement. J Immunol 2017; 198: 225.3-225.3.

119. O'Donnell KL, Meberg B, Schiltz J, Nilles ML, Bradley DS. Zika Virus-Specific IgY Results Are Therapeutic Following a Lethal Zika Virus Challenge without Inducing Antibody-Dependent Enhancement. Viruses 2019; 11. doi:10.3390/v11030301.

120. Wang X, Song L, Tan W, Zhao W. Clinical efficacy of oral immunoglobulin $\mathrm{Y}$ in infant rotavirus enteritis. Medicine (Baltimore) 2019; 98. doi:10.1097/MD.0000000000016100.

121. Yang Y, Wen J, Zhao S, Zhang K, Zhou Y. Prophylaxis and therapy of pandemic $\mathrm{H} 1 \mathrm{~N} 1$ virus infection using egg yolk antibody. J Virol Methods 2014; 206: 19-26.

122. Wallach MG, Webby RJ, Islam F, Walkden-Brown S, Emmoth E, Feinstein $\mathrm{R}$ et al. Cross-Protection of Chicken Immunoglobulin Y Antibodies against H5N1 and H1N1 Viruses Passively Administered in Mice $邓$. Clin Vaccine Immunol CVI 2011; 18: 1083-1090.

123. Wen J, Zhao S, He D, Yang Y, Li Y, Zhu S. Preparation and characterization of egg yolk immunoglobulin $Y$ specific to influenza B virus. Antiviral Res 2012; 93: 154-159.

124. Brocato R, Josleyn M, Ballantyne J, Vial P, Hooper JW. DNA Vaccine-Generated Duck Polyclonal Antibodies as a Postexposure Prophylactic to Prevent Hantavirus Pulmonary Syndrome (HPS). PLoS ONE 2012; 7. doi:10.1371/journal.pone.0035996. 
125. Haese N, Brocato RL, Henderson T, Nilles ML, Kwilas SA Josleyn MD et al. Antiviral Biologic Produced in DNA Vaccine/ Goose Platform Protects Hamsters Against Hantavirus Pulmonary Syndrome When Administered Post-exposure. PLoS Negl Trop Dis 2015; 9. doi:10.1371/journal.pntd.0003803.

126. Zhu N, Zhang D, Wang W, Li X, Yang B, Song J et al. A Novel Coronavirus from Patients with Pneumonia in China, 2019. N Engl J Med 2020; 382: 727-733.

127. Forni G, Mantovani A. COVID-19 vaccines: where we stand and challenges ahead. Cell Death Differ 2021; : 1-14.

128. Du L, He Y, Zhou Y, Liu S, Zheng B-J, Jiang S. The spike protein of SARS-CoV--a target for vaccine and therapeutic development. Nat Rev Microbiol 2009; 7: 226-236.

129. Sternberg A, Naujokat C. Structural features of coronavirus SARS-CoV-2 spike protein: Targets for vaccination. Life Sci 2020; 257: 118056 .

130. Lu Y, Wang Y, Zhang Z, Huang J, Yao M, Huang G et al. Generation of Chicken IgY against SARS-COV-2 Spike Protein and Epitope Mapping. J Immunol Res 2020. doi:10.1155/2020/9465398.

131. Somasundaram R, Choraria A, Antonysamy M. An approach towards development of monoclonal IgY antibodies against SARS CoV-2 spike protein (S) using phage display method: A review. Int Immunopharmacol 2020. doi: 85: 106654.

132. IgY Antibody Against Covid-19. Protheragen Inc. [Internet]. 2020. Available from: https://www.protheragen.com/pdf-down/ igy-antibody-against-covid-19/

133. ClinicalTrials.gov [Internet]. Stanford University. 2020 Sep 28. Identifier NCT04567810, A Phase 1 Study in Healthy Participants to Evaluate the Safety, Tolerability, and Pharmacokinetics of Single -Ascending and Multiple Doses of an Anti-Severe Acute Respiratory Syndrome Coronavirus 2 (SARS-CoV-2) Chicken Egg Antibody (IgY)(cited 2 Dec2020). Available from:https://clinicaltrials.gov/ct2/show/study/NCT04567810

134. ClinicalTrials.gov [Internet]. University of Colorado, Denver. 2017 Jan 4. Identifier NCT02385773, A Double Blind, Randomized, Placebo-Controlled Trial to Assess the Impact of the Nutritional Product PTM2O2 on Acute and Long-Term Recovery From Childhood Diarrheal Disease (cited 16 Dec2020). Available from:https://clinicaltrials.gov/ct2/show/NCT02385773

135. ClinicalTrials.gov [Internet]. ImmuniMed Inc. 2019 Oct 8 Identifier NCT04121169, Clinical Effectiveness of Egg-derived Polyclonal Antibodies (IM-01) for the Treatment of Mild-moderate Clostridium Difficile Infection (CDI) (cited 16 Dec2020). Available from: https://clinicaltrials.gov/ct2/show/NCT04121169

136. ClinicalTrials.gov [Internet]. Immunology Research Institute in Gifu. 2016 Mar 7. Identifier NCT02705885, Evaluation of IgY Antibody Effectiveness in Supportive Therapy of Periodontitis Patients (cited 13 May2021). Available from: https://clinicaltrials. gov/ct2/show/NCT02705885

137. ClinicalTrials.gov [Internet]. Chen X.. 2015 Jan 13. Identifier NCT02341352, Study on Children's Dental Caries Prevention and Mechanism (cited 16 Dec2020). Available from: https://clinicaltrials.gov/ct2/show/NCT02341352

138. ClinicalTrials.gov [Internet]. Immunology Research Institute in Gifu. 2016 Aug 29. Identifier NCTO2721355, Evaluation of a Health Food Supplement Containing Anti-Helicobacter Pylori Urease IgY Antibody on Patients With Chronic Gastritis in Hanoi, Vietnam (cited 16 Dec2020). Available from:https://clinicaltrials. gov/ct2/show/NCT02721355

139. ClinicalTrials.gov [Internet]. Institute of Gastroenterology and Hepatology, Vietnam. 2020 Jul 27. Identifier NCT04025983, Effectiveness of GastimunHp Plus in Supporting the Treatment of Peptic Ulcer Disease With Helicobacter Pylori Infection (cited 16 Dec2020). Available from: https://clinicaltrials.gov/ct2/show/ NCT04025983

140. ClinicalTrials.gov [Internet]. Immunsystem AB. 2016 Aug 31. Identifier NCT00633191, Post Marketing Study of Anti-pseudomonas $\lg Y$ in Prevention of Recurrence of Pseudomonas Aeruginosa Infections Infections in Cystic Fibrosis (CF) Patients (cited 2 Dec2020). Available from: https://clinicaltrials.gov/ct2/show/ study/NCT00633191
141. ClinicalTrials.gov [Internet]. Mukoviszidose Institut gGmbH. 2017 Jul 3. Identifier NCT01455675, Phase III Study to Evaluate Clinical Efficacy and Safety of Avian Polyclonal Anti-Pseudomonas Antibodies (IgY) in Prevention of Recurrence of Pseudomonas Aeruginosa Infection in Cystic Fibrosis Patients (cited 2 Dec2020). Available from: https://clinicaltrials.gov/ct2/show/ study/NCT01455675

142. ClinicalTrials.gov [Internet]. Uppsala University. $2011 \mathrm{Jul}$ 4. Identifier EUCTR2009-011446-26-SE, Chicken antibodies (IgY) for the eradication of ESBL-Klebsiella pneumoniae and E coli in carriers (cited 18 Dec2020). Available from: https://www.cochranelibrary.com/central/doi/10.1002/central/CN-01802509/ full?highlightAbstract=igy\%7Cigi

143. Leiva CL, Gallardo MJ, Casanova N, Terzolo H, Chacana P. Data for: IgY-technology (egg yolk antibodies) in human medicine: a review of patents and clinical trials. 2020; 2. doi:10.17632/9ryvhgm3d2.2.

144. Nordgren R, Dias Figueiredo M., Inventors; Merial, Inc., assignee:Compositions Containing Antimicrobial Igy Antibodies, for Treatment and Prevention of Disorders and Diseases Caused by Oral Health Compromising (ohc) Microorganisms. World Intellectual Property Organization patent WO 2016191389. 2016 Dec 1.

145. Dai Y-C, Jiang X., Inventors; Children's Hospital Medical Center Dai, assignee: Igy from Norovirus P Particles and Their Derivatives. World Intellectual Property Organization patent WO 2014011853. 2014 Jan 16

146. Pradip K M., Inventor; Immunimed Inc., assignee: Polyclonal antibodies against Clostridium difficile and uses thereof. United States patent US 154008029. 2015 Dec 24

147. Wei S, Yiqiang A, Qing G., Inventors; Xuzhou Biotechnology Co., Ltd., assignee: Preparation method of egg yolk antibody containing helicobacter pylori resisting IgY and application. Chinese patent CN 198343666. 2017 May 10.

148. Levin M, Vani E., Inventors; Karunya Institute Of Technology And Sciences, assignee: Chicken antibody generation against microbial pathogen bacillus cereus from human nail. Indian patent IN 283165535. 2019 Nov 28

149. Zhong Q, Wang B, Pu J, Fang X, Liao Z., Inventors; South China Agricultural University, assignee: Anti-vibrio parahaemolyticus chicken yolk antibody, preparation method and application thereof. Chinese patent CN 83537470. 2012 Jun 27.

150. Hui Z, Bai Z, Bao H, Ming H., Inventors; Jilin Modern Traditional Chinese Medicine Engineering Research Center Co., Ltd, assignee: Toothpaste capable of quickly relieving pain, diminishing inflammation, inhibiting bacteria, preventing dental caries and freshening breath. Chinese patent CN 145093694. 2015 Jul 1.

151. Jianfen C., Inventor; Shanghai Maxam Daily Chemical Co.,Ltd., assignee: Gingivitis and gingivitis ozostomia preventing mouthwash prepared by anti-porphyromonas gingivalis and IgY antibody with fusobacterium nucleatum specificity. Chinese patent CN 85796831. 2014 May 2014.

152. Aiguo B, Tongsen L, Cheng L., Inventors; Hangzhou Yasheng Biotechnology co., Ltd., assignee: Preparation method of composite IgY against periodontal disease pathogenic bacteria. Chinese patent CN 124076022. 2015 Oct 29.

153. Xiong Y., Inventor; Guangzhou Annel Biotechnology Co., Ltd. , Ltd, assignee: New anti-human papilloma virus (HPV) and endometritis preparation. Chinese patent CN 123483343. 2014 Sep 24.

154. Bao S, Yang R, Wang C, Cao T, Gong Q., Inventors; Shenzhen Yachen Intelligent Biological Engineering Co., assignee: Broad spectrum anti-HPV-LI and E6/E7-lgY, small molecule antibody and application thereof. Chinese patent CN 250122865. $2019 \mathrm{Jul}$ 26 .

155. Terzolo H. Aplicaciones de tecnología de las inmunoglobulinas de yema de huevo (IgY) de gallina. ResearchGate 2010; 173-183

156. Li X, Wang L, Zhen Y, Li S, Xu Y. Chicken egg yolk antibodies $(\lg Y)$ as non-antibiotic production enhancers for use in swine production: a review. J Anim Sci Biotechnol 2015; 6: 40.

157. Kovacs-Nolan J, Mine Y. Egg Yolk Antibodies for Passive Immunity. Annu Rev Food Sci Technol 2012: 3: 163-182. 
158. GastroMate. PRN Pharmacal. [Internet]. 2021. Available from: https://www.prnpharmacal.com/products/critical-care/ gastromate/

159. Bioinnovo IgY DNT Terneros. Vetanco[Internet]. 2017. Available from: https://www.vetanco.com/es/produto/bioinnovo-igy-dnt/

160. Products \& Services as Pet Food. Trouw Nutrition [Internet]. Available from: 2020.https://www.trouwnutritionusa.com/ en/products/

161. Horie K, Horie N, Abdou AM, Yang J-O, Yun S-S, Chun H-N et al. Suppressive effect of functional drinking yogurt containing specific egg yolk immunoglobulin on Helicobacter pylori in humans. J Dairy Sci 2004; 87: 4073-4079.

162. About i26. I26--Health. Arkion Life Sciences [Internet]. 2016. Available from: https://www.i26forhealth.com/i26-companion

163. Health Food Products.EW Nutrition [Internet]. 2020. Available from: https://ew-nutrition.com/healthfood/health-foodproducts/

164. Dan Biotech [Internet]. 2016. Available from: http:// www.danbio.com/en/sub.php? menucode $=0401$

165. Ovopron ${ }^{\circledR}$. Pharma Foods International Co., Ltd. [Internet]. 2019. Available from: https://www.pharmafoods.co.jp/en/products/ovopron

166. Muno-IgYTM .IGY Life Sciences [Internet]. 2021. Available from: https://www.ulprospector.com/es/na/Food/Detail/18617/524018/Muno-lgY

167. Ovalgen Products. EW Nutrition [Internet]. 2020. Available from: https://ew-nutrition.com/healthfood/health-food-products/ ovalgen/
168. Ulcer-Lock Product. Dan Biotech [Internet]. 2016. Available from: http://www.danbio.com/en/sub.php?menucode $=0402 \&$ category $=0201 \& i d x=17$

169. Gasto-Lock Product. Dan Biotech [Internet]. 2016. Available from: http://www.danbio.com/en/sub.php?menucode=0402\&category $=0201 \& i d x=20$

170. AtolB (Cosmetic effective for atopic dermatitis). Dan Biotech [Internet]. 2016. Available from: http://www.danbio.com/en/ sub.php? menucode $=0402 \&$ category $=0201 \& i d x=19$

171. Jensenius JC, Andersen I, Hau J, Crone M, Koch C. Eggs: conveniently packaged antibodies. Methods for purification of yolk IgG. J Immunol Methods 1981; 46: 63-68.

172. Harley C, Vieira-Pires RS. Antibody fragment technology and avian IgY antibodies: a powerful combination. 2016; 3: 62-66.

173. Brady D, Gaines S, Fenelon L, Mcpartlin J, O'Farrelly C. A Lipoprotein-derived Antimicrobial Factor from Hen-egg Yolk is Active Against Streptococcus Species. J Food Sci 2002; 67: 3096-3103.

174. Zhang H, Mine Y. CHAPTER 11:Antiviral Properties of Egg Components. In: Eggs as Functional Foods and Nutraceuticals for Human Health. Royal Society of Chemistry: Reino Unido, 2019, pp 198-210.

Received: 23 Febrero 2021

Accepted: 15 Junio 2021 